\title{
Study on Mechanical Properties and Damage Evolution Law of Secondary Destruction Induced by Simultaneous Unloading after the Peak of the Curve of Sandstone
}

\author{
Xiao Fukun, ${ }^{1,2}$ Liu Gang $\mathbb{D}^{1,2}$ and Cheng Qianlong $\mathbb{D}^{1,2}$ \\ ${ }^{1}$ Heilongjiang Ground Pressure \& Gas Control in Deep Mining Key Lab, Heilongjiang University of Science and Technology, \\ Harbin 150022, China \\ ${ }^{2}$ College of Mining Engineering of Hust, Heilongjiang University of Science and Technology, Harbin 150022, China
}

Correspondence should be addressed to Liu Gang; 814449714@qq.com

Received 16 May 2018; Accepted 15 July 2018; Published 16 August 2018

Academic Editor: Emanuele Reccia

Copyright (c) 2018 Xiao Fukun et al. This is an open access article distributed under the Creative Commons Attribution License, which permits unrestricted use, distribution, and reproduction in any medium, provided the original work is properly cited.

The research adopts the French ROCK600-50 three-axis experiment instrument and SH-II system to evaluate the acoustic emission (AE) peak of the rear axle of yellow sandstone by carrying out the confining pressure synchronous unloading experiment, and evolution of mechanical properties and characteristics of energy transformation and damage of a yellow sandstone, which is a twodamage process, the results of which have shown the following: (1) there are two damages appearing when the confining pressure is $5 \mathrm{MPa}, 10 \mathrm{MPa}$, and $20 \mathrm{MPa}$. In contrast, these two damages do not appear when the confining pressure is $30 \mathrm{MPa}$ and $40 \mathrm{MPa}$. The fracture degree and crack number of the two fractures are larger than those without two damages. (2) A failure stress release rate showed an obvious " $V$ " trend. With the increase of confining pressure, the stress release rate of the two failures is increasing. (3) By keeping the strain of the body constant, it is determined to be the first time to destroy the warning. The two failures of rock are predicted by the inflection point of the axial strain slope. No two failures occurred, and the strain unloading process showed two characteristics. (4) Meanwhile, with the increase of confining pressure, the energy released from the peak decreases first and then increases; the law of releasing energy from one failure and two destructions is the opposite. No damage occurred two times. As the confining pressure increases, there is a continuous decrease of the energy released from the peak. As the confining pressure increases, the release rate of the primary energy decreases at first and then increases, and the rate of energy released two times is increasing. The plasticity coefficient shows the trend of increasing first and then decreasing. (5) The damage degree of the second rupture is greater than the first rupture.

\section{Introduction}

Due to the rapid development of science and technology, construction projects based on rock mass engineering demonstrate a trend of increase in terms of scale, quantity, and also complexity. Due to the variability of the rock formation process, there are few cases of homogeneous and intact rock mass on the excavation face, as shown in Figure 1. The rock mass in the project has suffered various degrees of damage under the action of history stress. Historical stress leads to increase in defects. During the excavation process, the threedirectional stress of the surrounding rock gradually decreases and induces the ruptured rock mass to get further damaged. The failure of the rock is the consequence of the stress reaching the limit condition (after the peak), and the excavation process is bound to cause the unloading of the surrounding rock. Accordingly, there is a uniformity between the failure of the ruptured rock mass and the postpeak unloading of the rock sample. Excavation and unloading have a certain impact on the failure of rock mass; however, the main reason is that the rock mass is fractured by joints, cracks, faults, slip planes, and filled layers. Accordingly, the rock mass engineering problem is the second serious one leading to the destruction induced by the unloading of the residual strength in the crushing body. The unit in three-way stress equilibrium (including a large number of defects) changes to be in a threeway simultaneous unloading state due to excavation, as shown in Figure 1. The study on the secondary failure mechanics and 


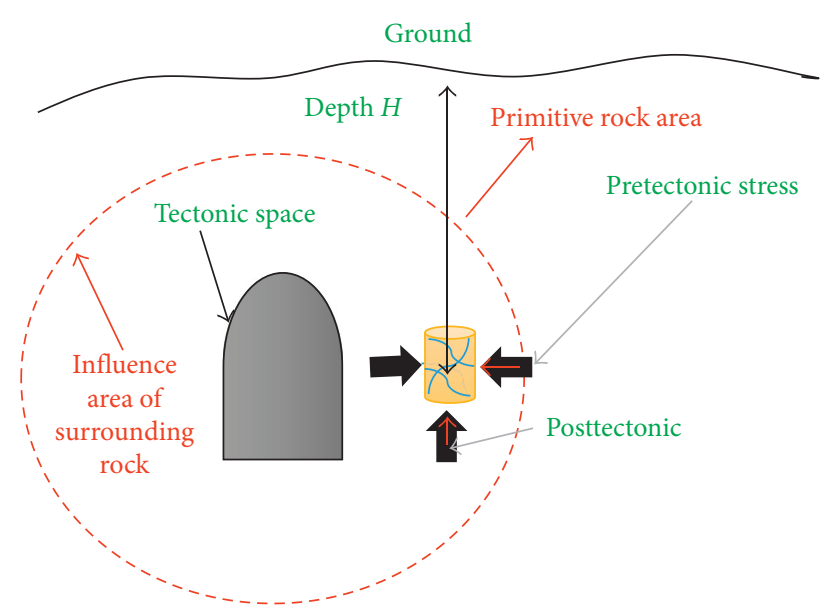

Figure 1: The unloading of the stress field before and after the spatial structure is constructed.

damage evolution induced by unloading is of great significance to the stability evaluation of surrounding rock.

Currently, massive studies have been made regarding the cyclic loading and unloading. Some achievements have already been made. For example, He et al. [1-4] made a study concerning the acoustic properties under true triaxial rock unloading conditions. Xu et al. [5] used the MTS press and acoustic emission system to monitor rock mechanics and acoustic properties under cyclic loading. Zhou et al. [6] carried out cyclic loading experiments on brittle rocks, presenting an analysis about the stress-strain curve characteristics, peak load, and damage characteristics. Deng et al. $[7,8]$ carried out a uniaxial cyclic loading experiment on sandstone, mainly focusing on the correlations between total energy, elastic strain energy, and dissipation energy, damage parameters and their correlations, and also the correlations between the loadingunloading response ratio and damage variables and regularities. The electromagnetic radiation was adopted by Song et al. [9] to monitor the deformation characteristics and capacity dissipation characteristics of coal samples under cyclic loading. Yin et al. [10] carried out triaxial tests on gas-bearing coal. Meanwhile, they also analyzed the mechanical characteristics of stress paths in the unloading direction with axial loading. Ray et al. [11] analyzed the strain and mechanical characteristics of sandstone under cyclic loading. Bagde and Petros [12] made a study about the fatigue characteristics and energy transformation of rock under cyclic loading. Zhao et al. [13] explored the damage and expansion characteristics of deep granite under triaxial cyclic loading. Liu et al. [14] carried out a research regarding the rock deformation and failure and the law of ultimate energy storage under four loading and unloading paths. Zhou et al. [15] carried out an in situ deep chamber in situ high-pressure true triaxial unloading experiment. Wang et al. [16] mainly attached their focus on the stress and volume strain of surrounding rock after dynamic unloading of the circular chamber under hydrostatic pressure. Wu et al. [17] conducted the indoor unloading rockburst experiment and numerical experiment with tunnel rockburst as the background. Xu et al. [18] implemented a research exploring the saturated sandstone cyclic loading pore water using MTS815 and analyzed the changing characteristics of the stress-strain curve during loading and unloading. Wang et al. [19] made a study regarding the distribution characteristics of unconfined uniaxial compression and initial hydrostatic pressure loading and unloading stress field through the theoretical analysis. Yang et al. [20] performed uniaxial cyclic loading tests on salt rock. Meanwhile, they also analyzed the modulus, Poisson's ratio, and energy dissipation law. Xiao et al. [21-23] explored the energy conversion during the rupture of coal and rock mass. Liu et al. [24,25] analyzed the energy variation characteristics of the combined coal and granite destruction processes. Yang et al. [26] analyzed the damage experiment of uniaxial acoustic emission. Liu et al. [27] analyzed mining-induced inrushes from subjacent water conducting karst collapse columns in northern China. Li et al. [28] analyzed rock brittleness on the hydraulic fractures in the shale reservoir.

It can be seen from above that previous studies mainly focus on the mechanical characteristics, deformation characteristics, and energy conversion rules under single and triaxial cyclic loading and unloading paths. However, most of them focus on changing the loading-unloading path to simulate the on-site working conditions in the prepeak period and do not consider the actual surrounding rock itself as a rupture body. After the space is constructed, the microcells will be in a three-way synchronous unloading state and further rupture of the rock mass is induced. Therefore, aforementioned research studies actually cannot reflect the rupture characteristics of surrounding rock under objective and actual working conditions. In this paper, we use the Top Industrie ROCK600-50 adaptive multifield coupling experiment instrument of France and SH-II health monitoring system of American Acoustics Co. Ltd. to carry out the postpeak synchronous unloading experiment of the yellow sandstone at the axial and the confining pressure. The mechanical properties, energy conversion characteristics, and damage evolution of the yellow sandstone during primary failure and secondary failure are obtained. It focuses on the identification of precursory information of fractured rock mass, providing the basic data for the monitoring and the controlling of the stability of underground rock mass.

\section{Experimental Methods}

2.1. Experimental Sample Preparation. In order to ensure the validity of the experimental results, yellow sandstone is processed according to the determination method of coal and rock deformation parameters (GB/T 23561.8-2009). Standard size is $\Phi 50 \times 100 \mathrm{~mm}$. The bulk density was finally determined at $2.16 \mathrm{~g} / \mathrm{m}^{3}$ based on the wax seal method. The strength was $74.8 \mathrm{MPa}$, while the elastic modulus was $12.8 \mathrm{GPa}$ and Poisson's ratio was 0.28 by the uniaxial compression deformation test. It is shown from the detection of the internal structures through the industrial CT that the yellow sandstone is homogeneous and dense. When the rock samples are used for ultrasonic testing, the $\mathrm{P}$ wave velocity is approximately $3900 \mathrm{~m} / \mathrm{s}$ and the $\mathrm{S}$ wave velocity is approximately $3100 \mathrm{~m} / \mathrm{s}$, which ensures that the rules for the exploration of these batches are reliable. The basic information of rock samples is shown in Table 1. Due to the large number of rock samples, 
TABLE 1: Basic information of yellow sandstone.

\begin{tabular}{lccccc}
\hline Numbering & $\begin{array}{c}\text { Diameter } \times \text { height } \\
(\mathrm{mm})\end{array}$ & Mass $m(\mathrm{~g})$ & $\begin{array}{c}\text { Confining pressure } \sigma 3 \\
(\mathrm{MPa})\end{array}$ & $\begin{array}{c}\text { P wave speed } \\
(\mathrm{m} / \mathrm{s})\end{array}$ & $\begin{array}{c}\text { Loading and unloading } \\
\text { speed }(\mathrm{MPa} / \mathrm{min})\end{array}$ \\
\hline SZ-24 & $49.22 \times 100.09$ & 438.2 & 5 & 3910 & 1 \\
SZ-5 & $50.30 \times 100.10$ & 434.7 & 10 & 3895 & 1 \\
SZ-10 & $50.02 \times 100.02$ & 436.2 & 20 & 3927 & 1 \\
SZ-21 & $50.20 \times 101.30$ & 436.6 & 30 & 3896 & 1 \\
SZ-18 & $50.19 \times 101.61$ & 436.4 & 40 & 3908 & 1 \\
\hline
\end{tabular}

only the typical analysis was selected to give specific information. The fracture morphology of triaxial test specimens is shown in Figure 2. As the depth of burial increases, the ground stress increases correspondingly. Meanwhile, the local main stress in the local area can reach $40 \mathrm{MPa}$ or even more. For the representativeness and extensiveness of the research problem, the hydrostatic pressure of the triaxial test was designed to be $5 \mathrm{MPa}, 10 \mathrm{MPa}, 20 \mathrm{MPa}, 30 \mathrm{MPa}$, and $40 \mathrm{MPa}$, respectively. Due to space limitations, only representative rock samples were selected for analysis.

$$
\begin{aligned}
W_{a} & =\int_{G}^{P} \sigma d \varepsilon, \\
W_{b} & =W_{1 P}+W_{2}+W_{3 P}+W_{4}, \\
W_{1 P} & =\int_{P}^{R} \sigma d \varepsilon, \\
W_{2 \cdot 4} & =\int_{R}^{S} \sigma d \varepsilon, \\
W_{3 P} & =\int_{S}^{N} \sigma d \varepsilon, \\
v_{W} & =\frac{w_{i}}{t_{i}}, \\
W_{\mathrm{S}} & =W_{\text {accumulation before the peak }}-W_{\text {release after the peak }}, \\
K_{\mathrm{P}} & =\frac{W_{\text {accumulation before the peak }}}{W_{\text {GHIT }}}
\end{aligned}
$$

2.2. Experimental Equipment. The experiment used the ROCK600-50 multifield coupling mechanics test system produced by the French Top Industrie company. Additionally, to monitor the rock-breaking process, the SH-II acoustic emission system was adopted in the experiment. The device composition and arrangement relationship are shown in Figure 3. In order to correct the moment of rock rupture and information, the acoustic emission sensor 1 is arranged on the base of the press, while data generated from the processes of loading and unloading are collected. The acoustic emission sensor 2 is arranged on the side wall of the confining pressure chamber. Since the signal is significantly attenuated in the hydraulic oil, acoustic emission signals can only be acquired when they are broken. The sensor is fixed in

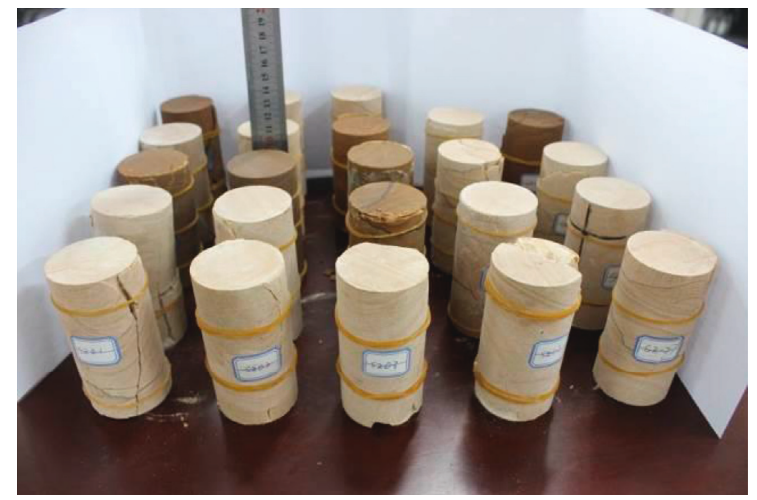

FIGURE 2: Fracture photos of rock samples.

the corresponding position with high-strength magnets, during the process of which Vaseline coupling sensors and contact surfaces have been used. The acoustic emission threshold is $40 \mathrm{~dB}$.

2.3. Experimental Scheme. A servo pump was adopted in the three-axis synchronous unloading test to load the test piece. First, rock samples were loaded under hydrostatic pressures of $5 \mathrm{MPa}, 10 \mathrm{MPa}, 20 \mathrm{MPa}, 30 \mathrm{MPa}$, and $40 \mathrm{MPa}$ at a rate of $1 \mathrm{MPa} / \mathrm{min}$. To ensure stable transition of the rock sample system and to discriminate acoustic emission effects, the hydrostatic pressure is maintained for a certain period of time. Afterward, the deviatoric stress is increased at a rate of $1 \mathrm{MPa} / \mathrm{min}$ until the rock sample is destroyed once. Then, the confining pressure is kept constant for a while. It requires to unload the axial pressure and confining pressure simultaneously after a certain value is reached while secondary damage is induced. After the destruction, it is stabilized again and unloaded again synchronously until the rock sample is no longer stressed. From the initial loading to the completion of the uninstallation, acoustic emission monitoring is used throughout. The experimental path is shown in Figure 4.

2.4. Theoretical Basis. In order to effectively collect and monitor the experimental data, the fracture process of rock damage will be analyzed from various angles, including the change of strain field, stress field, and energy field transformation and the evaluation of yellow sandstone damage by using the acoustic emission technology. In the strain field analysis, the variation characteristics of the corresponding strains at different initial hydrostatic pressures are analyzed using the axial strain-annular strain-body strain and time variation law. Body strain and axial strain are used to predict 


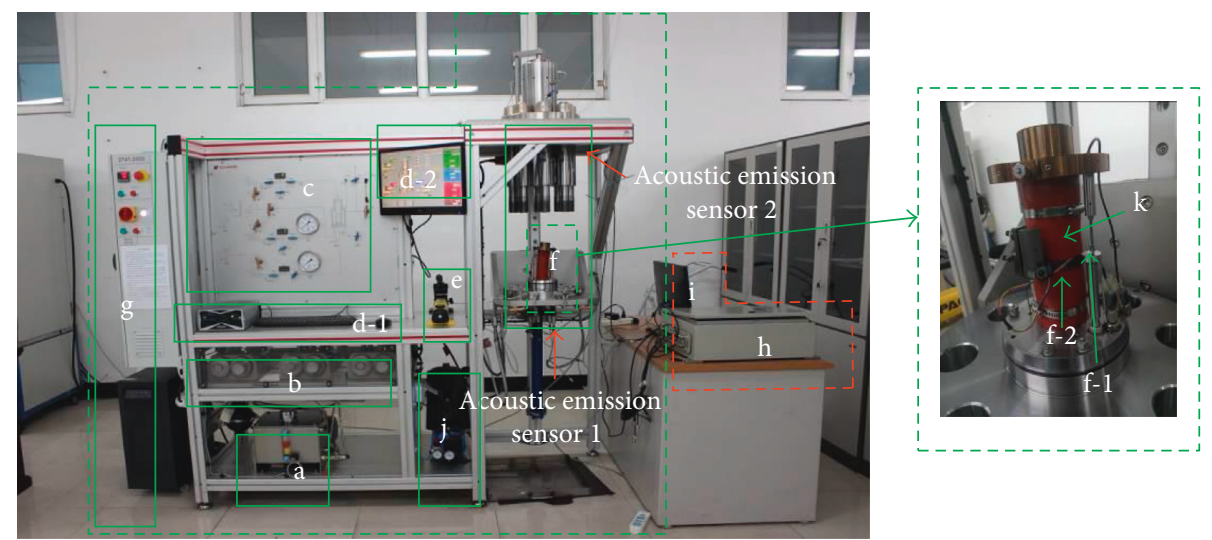

FigURE 3: Synchronous unloading mechanical experiment device and acoustic acquisition device. a: oil source; b: axis, enclosure, pore water loading pump; c: monitoring and control panel; d: computer acquisition control system (d-1: control system display and d-2: the host of the control system); e: base lift pump; f: base (f-1: axial sensor and f-2: ring sensor); g: power; h: acoustic emission host; i: acoustic emission display system; $\mathrm{j}$ : pressure pump for confining pressure room; $\mathrm{k}$ : rock sample.

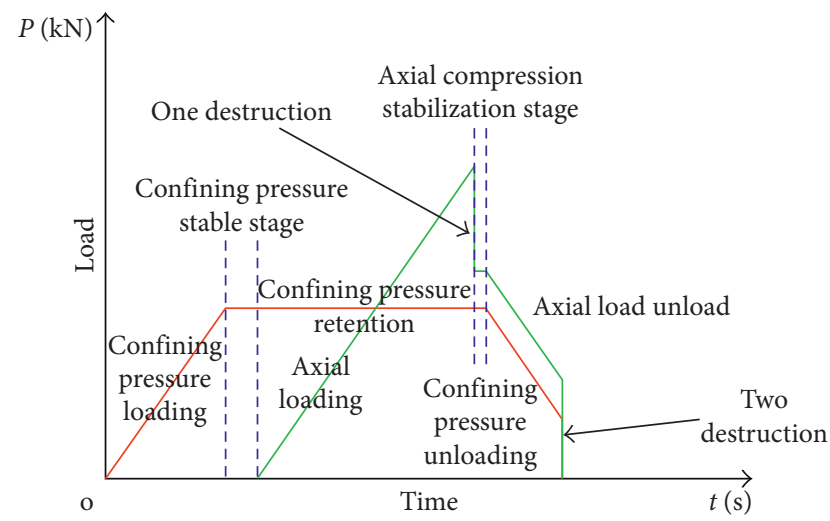

FIgURE 4: Synchronous unloading experimental path.

rock breakage. In the energy analysis, stress-strain curves and stress-time curves are used to analyze the characteristics of energy accumulation, transformation, and release under different hydrostatic pressures and the characteristics of the plasticity coefficient and energy release rate of rock. When it comes to the damage analysis, it adopts acoustic emission energy to characterize the damage variables of the rock. An analysis about the damage evolution process is made. Figure 5 shows the relationship between energy accumulation, conversion, and release. It can be found from the figure that the energy calculation uses the stress-strain curve's integral form, in which the red line is the integral calculation energy. The unit of energy derived from the dimensions is $\mathrm{kJ} / \mathrm{m}^{3}$, and the specific calculation formulas are shown in (1)-(8).where $W_{a}$ is the total strain energy accumulated before the peak and $W_{b}$ refers to the strain energy released after the peak, while $W_{1 P}$ means the strain energy released from the first failure. $W_{2}$ and $W_{4}$ represent the strain energy released by synchronous unloading, while $W_{3 P}$ is the second failure. $v_{W}$ is the rate at which strain energy is released. $w_{i}$ is the strain energy released at the time after the peak. $t_{i}$ is the time elapsed after a peak was destroyed or unloaded. It has been marked in Figure 5. In the figure, $W_{\mathrm{S}}$ represents the

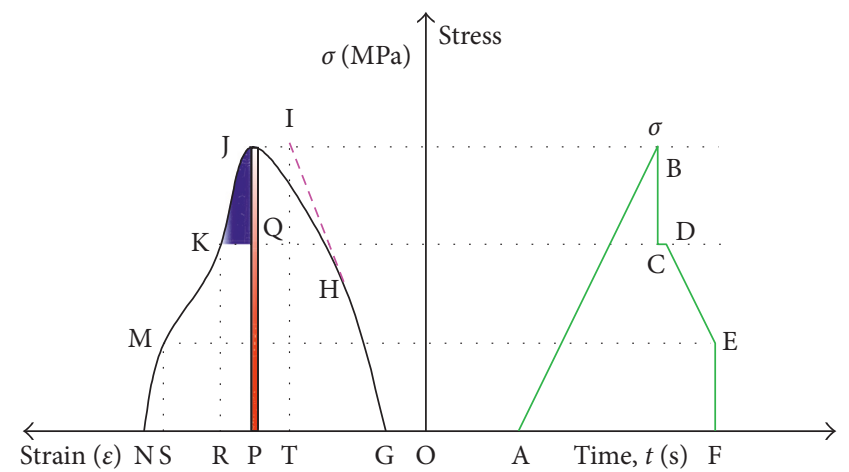

FIgURE 5: Diagram of energy accumulation, transformation, and release.

remaining energy of the rock sample destruction process. $K_{\mathrm{P}}$ is the rock plasticity coefficient.

Based on the research, the cracking energy of the rock and the strain energy released during the cracking process can be reflected through the energy in the acoustic emission characteristic parameters. This paper will use acoustic emission energy and cumulative energy to deduce the evolution of the rock triaxial damage.

The traditional damage variable is defined by the area ratio. This paper uses the deformation ratio method. The formula is

$$
D=\frac{\varepsilon_{0}}{\varepsilon},
$$

where $\varepsilon_{0}$ represents the change of strain in the process of rock entering into complete destabilization and $\varepsilon$ is the maximum strain corresponding with the complete failure of rock samples.

If the total energy collected by the acoustic emission during the complete fracture of the rock specimen is assumed to be $W$, the energy released by the rupture of the microelements correspondingly is

$$
M_{W}=\frac{W}{\varepsilon} \text {. }
$$


When the damage volume reaches $\varepsilon_{0}$, the accumulated energy reaches $W_{D}$ :

$$
W_{D}=\varepsilon_{0} * M_{W}=\varepsilon_{0} * \frac{W}{\varepsilon},
$$

where

$$
D=\frac{\varepsilon_{0}}{\varepsilon}=\frac{W_{D}}{W} .
$$

According to the aforementioned theory, the authors will analyze the characteristics of energy conversion and damage evolution during secondary rock failure induced by simultaneous unloading. The energy conversion parameters are shown in Table 2.

\section{Analysis of Synchronous Uninstallation Results}

3.1. Analysis of Characteristics of Simultaneous Unloading Stress Change. In order to be truly close to the rock mass excavation process, to simulate the on-site stress field changes, and also to obtain the rock body failure evolution process, the rock sample is first loaded to the peak state in the experiment. Later, confining pressure-axial pressure is unloaded synchronously to the state of zero stress, during the whole process of which synchronous acoustic emission is adopted for monitoring. A total of 25 specimens were subjected to the above stress path experiment. There are two situations being obtained from the analysis of the experimental results. One is that the secondary rupturing occurs under a certain stress state for the synchronous unloading, and the other is that no secondary damage occurred after unloading synchronously. Typical curves and broken photos are shown in Figure 6.

Figure 6 records the changes of the field over time and the fracture pattern of the rock sample at the moment of rupture. Besides, Figure 6(a) shows the process information corresponding to $5 \mathrm{MPa}$ confining pressure. In order to ensure that the rock sample is in a stable state and the quality of the acoustic emission signal can be improved, the confining pressure is applied for 300 seconds before the application of deviatoric stress. The peak deviator stress at failure was $91.22 \mathrm{MPa}$. The initial failure stress was reduced by $60.58 \mathrm{MPa}$, which took 3.89 seconds. The difference between stress and confining pressure after the initial destruction was $25.73 \mathrm{MPa}$. In order to ensure the stability of the stress and crack propagation, the converging pressure and axial pressure were unloaded synchronously when there is no change occurring on the observation curve. The stability lasted for $250 \mathrm{~s}$, and the stress changed by $2.23 \mathrm{MPa}$. The corresponding confining pressure in the secondary failure was $0.94 \mathrm{MPa}$. It took $2.32 \mathrm{~s}$ to reduce the stress by 4.59 MPa. The difference between stress and confining pressure after secondary destruction was $4.86 \mathrm{MPa}$. After the confining pressure was unloaded to zero, the residual stress was 3.98 MPa. It can be seen from the conventional triaxial test that there were a typical single oblique shear failure and a splitting failure shown from typical ruptures. According to this, the primary damage is obtained from the master crack, while the secondary fracture is from the microcrack. The figure has identified the oblique shear damage occurring correspondingly with the first breakage and the drop below the pattern. There were three shear cracks and one longitudinal crack in different directions in the secondary fracture. Figure 6(b) shows the process information when the confining pressure is $10 \mathrm{MPa}$. The peak deviator stress at failure was $126.11 \mathrm{MPa}$. The first failure stress was reduced by $34.42 \mathrm{MPa}$, which took 4.92 seconds. The difference between stress and confining pressure after the first destruction was $81.69 \mathrm{MPa}$. Such a stability lasted for $900 \mathrm{~s}$, and the stress changed by $2.78 \mathrm{MPa}$. The corresponding confining pressure during the secondary failure was $4.58 \mathrm{MPa}$. The stress was reduced by $20.48 \mathrm{MPa}$, which took $4.09 \mathrm{~s}$. The difference between stress and confining pressure after secondary destruction was $30.83 \mathrm{MPa}$. The residual stress after the confining pressure was unloaded to zero was $17.66 \mathrm{MPa}$. The figure has identified the oblique shear failure occurring during the first break and also the drop of the small pieces to the bottom of the pattern. There were two shear cracks and one horizontal crack in two different directions in the second rupture. There were cracks. Meanwhile, partial shear spalling occurred. Figure 6(c) displays the corresponding process information when the confining pressure was $20 \mathrm{MPa}$. The peak deviator stress at failure was $156.25 \mathrm{MPa}$. The initial failure stress was reduced by $53.61 \mathrm{MPa}$, which took $4.36 \mathrm{~s}$. The difference between stress and confining pressure after the initial destruction was $80.63 \mathrm{MPa}$. The stability lasted for $200 \mathrm{~s}$, while the stress changed by $2.15 \mathrm{MPa}$. The confining pressure corresponding to the secondary failure was 2.9 MPa. Stress was reduced by $19.90 \mathrm{MPa}$, which took $1.78 \mathrm{~s}$. The difference between stress and confining pressure after secondary destruction was $0 \mathrm{MPa}$. The residual stress was $0 \mathrm{MPa}$ after the confining pressure was unloaded to zero. The figure has identified the oblique shear failure occurring during the initial break. One shear crack and one longitudinal crack appeared in the secondary fracture. Figure 6(d) presents the process information corresponding to $30 \mathrm{MPa}$ confining pressure. The peak deviator stress at failure was 198.78 MPa. Meanwhile, it took $4.41 \mathrm{~s}$ to reduce the failure stress by 87.65 MPa. The difference between the stress and the confining pressure after the destruction was $80.99 \mathrm{MPa}$. The stability lasted for $200 \mathrm{~s}$, the stress changed by $2.56 \mathrm{MPa}$, and the residual stress after confining pressure was unloaded to zero was $5.91 \mathrm{MPa}$. It can be seen from the figure that the oblique shear failure occurred at the time of cracking. This also confirms the abovementioned argument regarding secondary cracking. Figure 6(e) shows the process information corresponding to a confining pressure of $40 \mathrm{MPa}$. The peak deviator stress at break was $224.90 \mathrm{MPa}$. The failure stress was reduced by $67.68 \mathrm{MPa}$ and it took $2.57 \mathrm{~s}$. The difference between the stress after the break and the confining pressure was 118.18 MPa. The stability lasted for $350 \mathrm{~s}$, leading to the stress change of 4.69 MPa, while the residual stress after confining pressure was unloaded to zero was $11.34 \mathrm{MPa}$. In the figure, it has been identified that there was an oblique shear damage.

The secondary failure of the confining pressure of $5 \mathrm{MPa}$ is 4 cracks ( 3 oblique shearing and 1 stretching), and the unloading confining pressure value of the secondary failure 
TABLE 2: Energy conversion parameter table.

\begin{tabular}{|c|c|c|c|c|c|c|c|c|c|c|c|c|c|}
\hline $\begin{array}{l}\text { Confining } \\
\text { pressure }(\mathrm{MPa})\end{array}$ & $\begin{array}{c}W_{a} \\
\left(\mathrm{~kJ} / \mathrm{m}^{3}\right)\end{array}$ & $\begin{array}{c}W_{b} \\
\left(\mathrm{~kJ} / \mathrm{m}^{3}\right)\end{array}$ & $\begin{array}{c}W_{1 P} \\
\left(\mathrm{~kJ} / \mathrm{m}^{3}\right)\end{array}$ & $\begin{array}{c}W_{2} \\
\left(\mathrm{~kJ} / \mathrm{m}^{3}\right)\end{array}$ & $\begin{array}{c}W_{3 P} \\
\left(\mathrm{~kJ} / \mathrm{m}^{3}\right)\end{array}$ & $\begin{array}{c}W_{4} \\
\left(\mathrm{~kJ} / \mathrm{m}^{3}\right)\end{array}$ & $t_{1}(\mathrm{~s})$ & $t_{2}(\mathrm{~s})$ & $\begin{array}{c}\begin{array}{c}W_{v 1} \\
\left(\mathrm{~kJ} / \mathrm{m}^{3} / \mathrm{s}\right)\end{array} \\
\end{array}$ & $\begin{array}{c}W_{v 2} \\
\left(\mathrm{~kJ} / \mathrm{m}^{3} / \mathrm{s}\right)\end{array}$ & $\begin{array}{c}W_{\mathrm{S}} \\
\left(\mathrm{kJ} / \mathrm{m}^{3}\right)\end{array}$ & $K_{\mathrm{P}}$ & $\begin{array}{r}W_{\text {JHI }} \\
\left(\mathrm{kJ} / \mathrm{m}^{3}\right)\end{array}$ \\
\hline 5 & 41.58 & 57.08 & 43.73 & 8.48 & 2.43 & 2.44 & 3.89 & 2.32 & 11.24 & 1.05 & 0 & 0.87 & 47.74 \\
\hline 10 & 80.51 & 38.39 & 18.30 & & 6.33 & 13.59 & & & 3.72 & 1.5 & 42.12 & 0.98 & 81.9 \\
\hline 20 & 118.00 & 100.63 & 46.07 & 48.60 & 5.96 & 0 & 4.36 & 1.78 & 10.57 & 3.35 & 17.37 & 1 & 117.53 \\
\hline 30 & 178.20 & 36.97 & 75.28 & 3.69 & 0 & -42.25 & 4.41 & 0 & 17.07 & 0 & 141.23 & 0.91 & 196.91 \\
\hline 40 & 227.88 & 4.88 & 68.19 & 10.45 & 0 & -3.76 & 2.57 & 0 & 26.53 & 0 & 223.00 & 0.92 & 248.82 \\
\hline
\end{tabular}

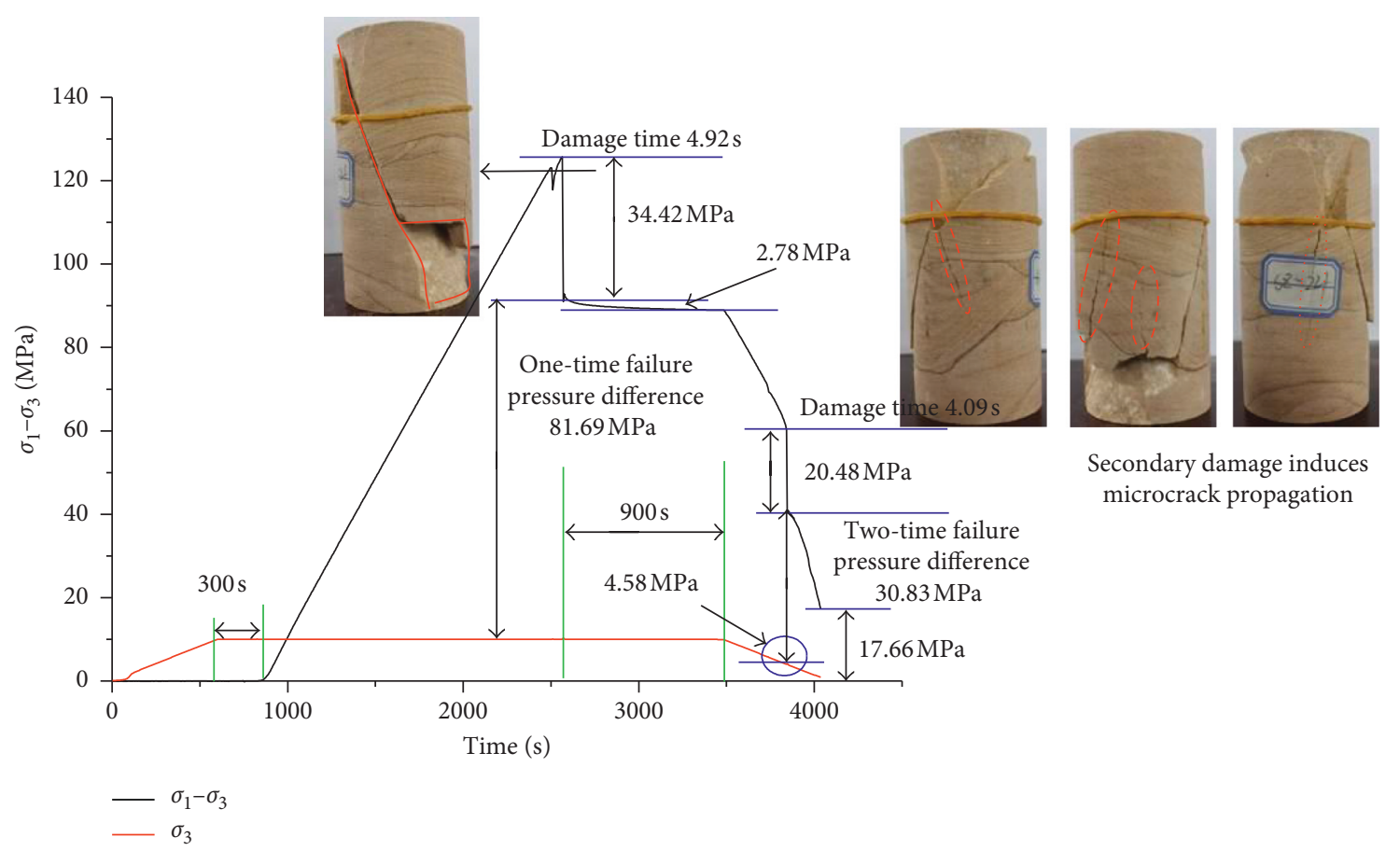

(a)

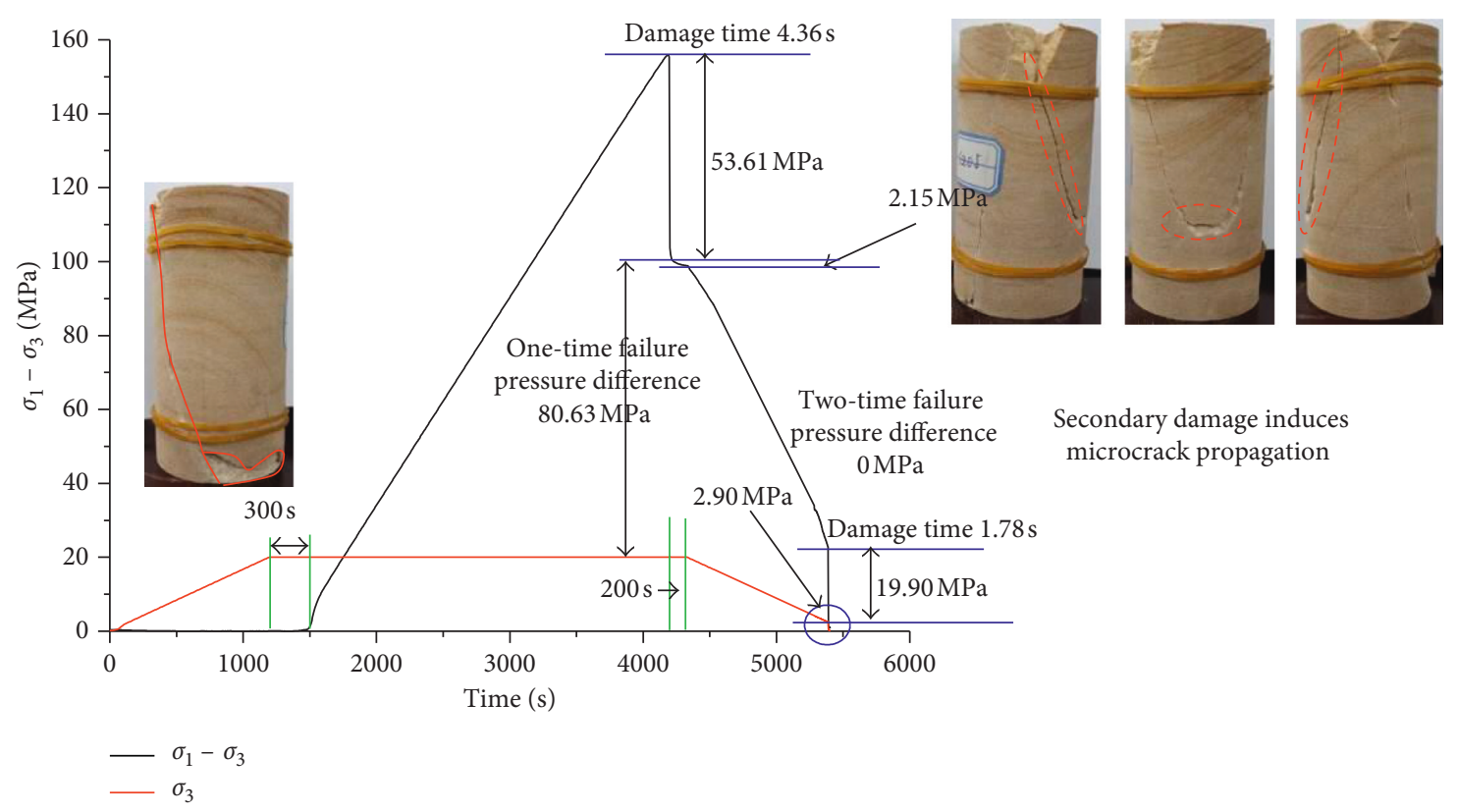

(b)

Figure 6: Continued. 


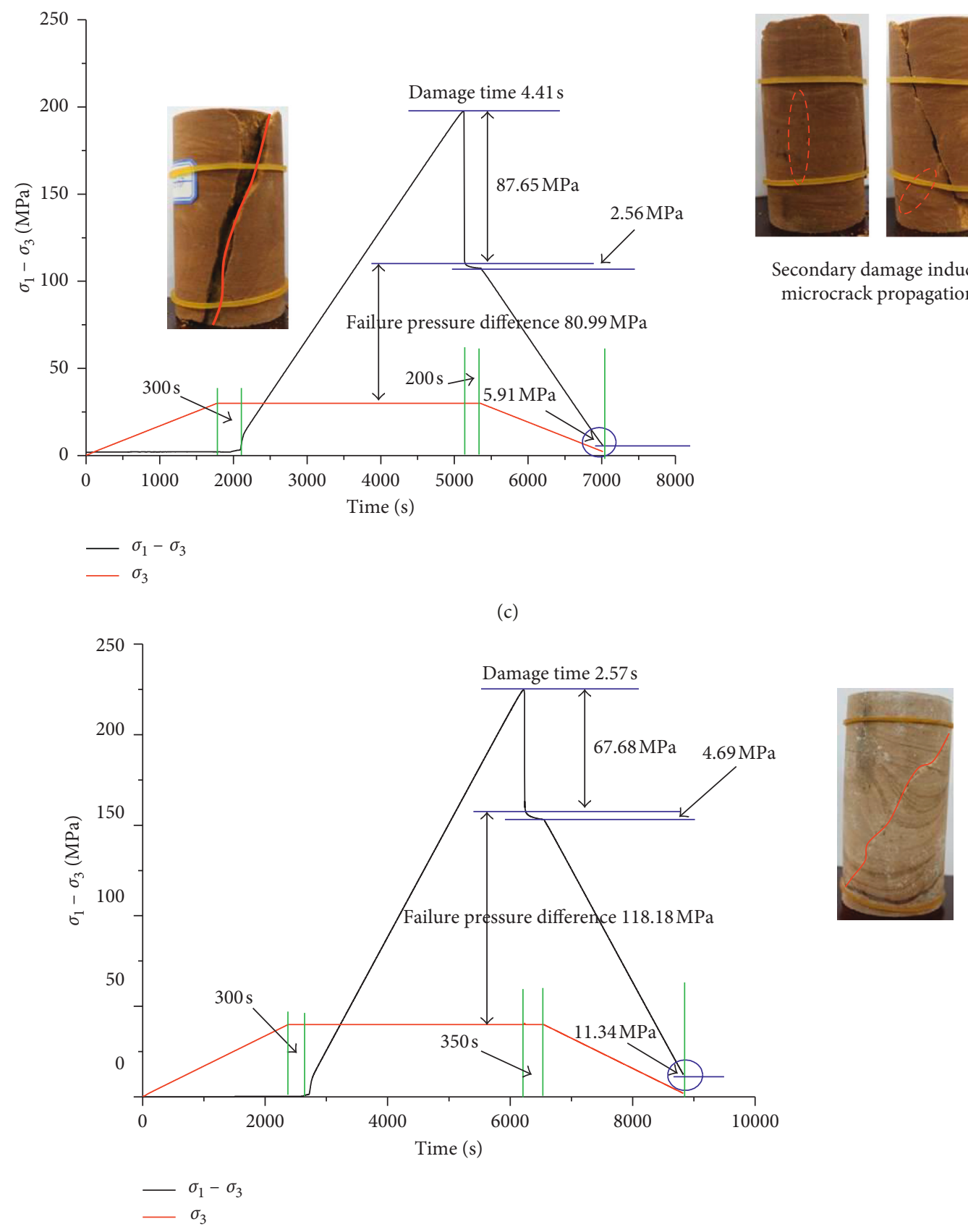

(d)

Figure 6: Continued. 


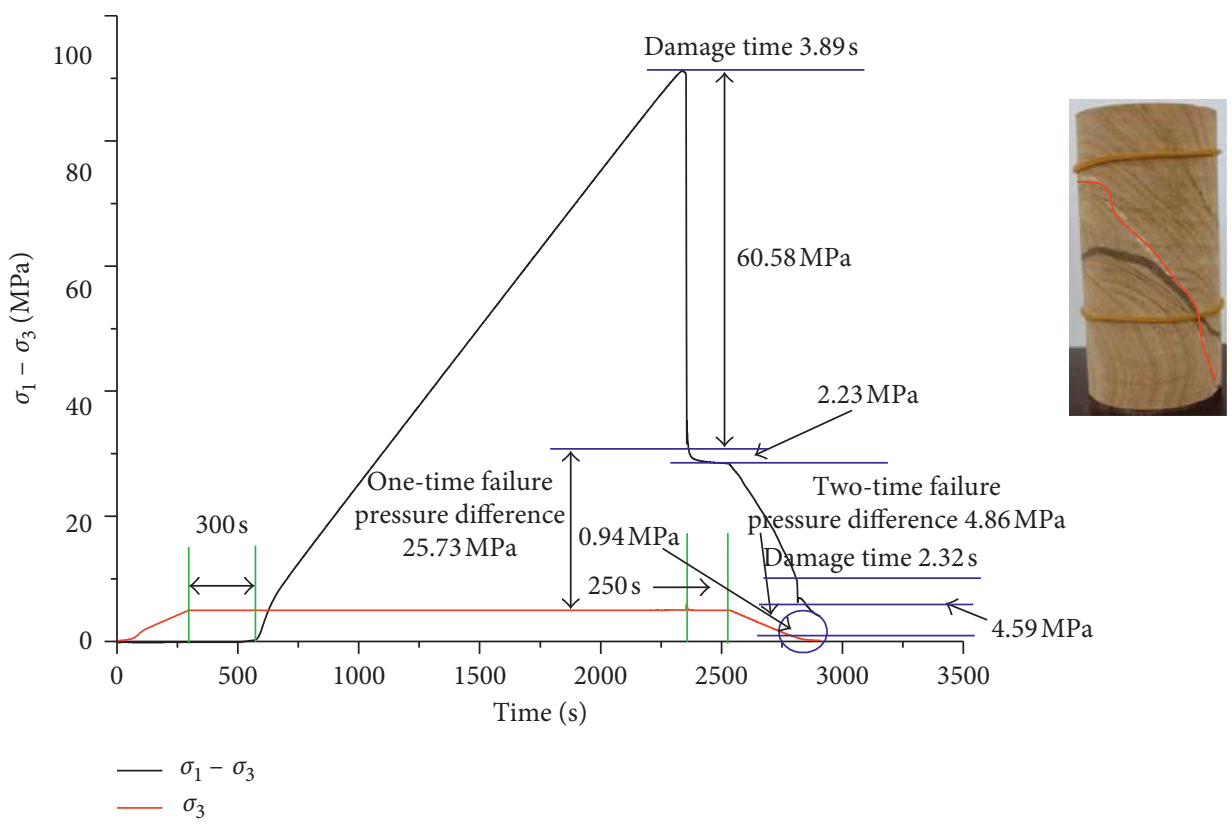

(e)

FiguRE 6: Stress-time rupture relation diagram. Change law of the stress-time curve of surrounding rock at (a) $5 \mathrm{MPa}$, (b) $10 \mathrm{MPa}$, (c) $20 \mathrm{MPa}$, (d) $30 \mathrm{MPa}$, and (e) $40 \mathrm{MPa}$.

is $0.94 \mathrm{MPa}$. The secondary failure of the confining pressure of $10 \mathrm{MPa}$ is 3 cracks (2 oblique shearing and 1 straight shearing), and the unloading confining pressure value of the secondary failure is $4.58 \mathrm{MPa}$. The secondary failure of the confining pressure of $20 \mathrm{MPa}$ is 2 cracks ( 1 oblique shear and 1 tensile), and the unloading confining pressure value of the secondary failure is $2.9 \mathrm{MPa}$. No secondary damage occurred at pressures of $30 \mathrm{MPa}$ and $40 \mathrm{MPa}$. With the increase of the initial confining pressure, the total number of cracks and the number of oblique shear cracks generated during the secondary damage are reduced. When the secondary damage confining pressure is large $(4.58 \mathrm{MPa})$, a straight shear crack appears at this time. When the secondary failure confining pressure is small (2.9 $\mathrm{MPa}$ and $0.94 \mathrm{MPa})$, one tensile crack appears at this time. According to this, the crack type has a certain correlation with the secondary damage confining pressure value.

When the confining pressure was $5 \mathrm{MPa}, 10 \mathrm{MPa}$, and $20 \mathrm{MPa}$, secondary failure occurred. In contrast, there was no secondary failure when the confining pressure was $30 \mathrm{MPa}$ and $40 \mathrm{MPa}$, indicating that the rock is easily destroyed again during excavation and unloading of low confining pressure. This places higher demands on the support and stability control of the surrounding rock. It is shown that the stability of unloading rock mass is better under high confining pressure. Meanwhile, the self-supporting capacity of surrounding rock is strong. At the same time, the accumulated elastic energy is also large, and it may cause serious disasters under unsynchronized unloading.

In order to explore the characteristics of the destruction process, the confining pressures of the three groups of rock samples with secondary failures were set as low confining pressures, while the confining pressures of rock samples without secondary destruction were set as high confining pressures. It is shown from the analysis of the first destructive stability interval that the pressure drop in the $40 \mathrm{MPa}$ stable interval is about twice that in the other confining pressure stable interval. It shows that a period of adjustment of about $200 \mathrm{~s}$ is required after rock failure under confining pressure. A pressure drop of $2.43 \mathrm{MPa}$ occurs. With the increase of mining depth (40 MPa confining pressure), the required stabilization time and pressure drop are increasing. The fractures and cracks of the three rock specimens with secondary failure are larger than those of the two rock samples without secondary damage. The average time required for the initial failure of rock samples was $4.03 \mathrm{~s}$. Except that the destruction time is small when the confining pressure is $40 \mathrm{MPa}$, the results of other groups are similar, which shows that it takes a certain period of time for the main crack to extend to the penetration. The time required for cracking under high confining pressure is relatively short. The average value of the instantaneous decline of the primary failure of the rock sample with secondary failure is $49.54 \mathrm{MPa}$, while the instantaneous value of the rock failure without secondary damage is 77.67 $\mathrm{MPa}$. The initial failure of the rock sample is more thorough under the high confining pressure. Meanwhile, it is not easy to cause secondary damage. The unloading crack under low confining pressure will continue to expand and induce secondary damage. At this time, the result is corresponding to the failure form of the rock sample. With the increase of confining pressure, the pressure difference during the initial destruction generally showed an increasing trend. However, the range of $10 \mathrm{MPa}$ and $20 \mathrm{MPa}$ did not change much. After the confining pressure is unloaded to zero, the residual stress does not demonstrate a certain 
regularity under low confining pressure, which indicates that the residual stress in some areas is relatively large and the residual stress in some areas is small, which poses a great challenge to the stability control of the project. It can be found that the residual stress is stable under high confining pressure, which has certain guiding effect on the stability control of rock mass. In the secondary demolition induced by synchronous unloading, the corresponding confining pressure value, the pressure difference during secondary failure, the time of secondary failure, and the stress reduction value during failure are all different. Therefore, it suggests that the problem of secondary failure pressure in the project needs to be handled with care. The decline in stress is bound to be accompanied by the release of energy. The speed of stress reduction is the key to causing disasters. Based on this, the stress release rate during the primary and secondary failure of yellow sandstone under different confining pressures is analyzed. The curve fitting results are shown in Figure 7. Through analysis, it can be seen that the stress release rate of the initial failure demonstrates a " $/$ " trend. The stress release rate of confining pressure in the range of $5 \mathrm{MPa}$ and $10 \mathrm{MPa}$ decreased, while the stress release rate in the range of $10 \mathrm{MPa}$ to $40 \mathrm{MPa}$ showed a linear increase. Attention should be attached to the destruction of disasters brought about by transients and deviants under the high confining pressure. The confining pressure (unloading) can reduce and change the mechanical properties of surrounding rocks. The fitting of several groups of rock specimens with secondary damage shows that the stress release rate increases as the confining pressure increases. The initial stress of the surrounding rock, to which excavation unloading can cause secondary destruction, is relatively large. Corresponding measures should be taken to reduce the stress release rate and ensure the stability of the project.

3.2. Analysis of Distortion Change Characteristics in Synchronized Unloading. In order to grasp the variation of the deformation before and after the unloading of the triaxial test, the characteristics of the axial strain, hoop strain, and body strain after simultaneous unloading under different initial confining pressures were analyzed with time as parameters. Due to the way of hydrostatic pressure loading in the early stage, the axial deformation took the average of $D_{2}$ and $D_{3}$.

Figure 8 presents the strain-time curve under different confining pressures. At the initial stage of loading to $5 \mathrm{MPa}$ hydrostatic pressure, there was an increase of the axial deformation and a decrease of the circumferential deformation. The axial variation was larger than the circumferential direction. The rock sample was continuously compacted under the influence of external stress. The overall volume was continuously decreasing. During the process of maintaining the hydrostatic pressure at $5 \mathrm{MPa}$, the axial strain and the hoop strain did not change, and the body strain was 0.28 . When deviatoric loading was applied, the axial deformation increases and the circumferential deformation continued to expand. At $1464 \mathrm{~s}$, the circumferential deformation exceeded the initial value and continued

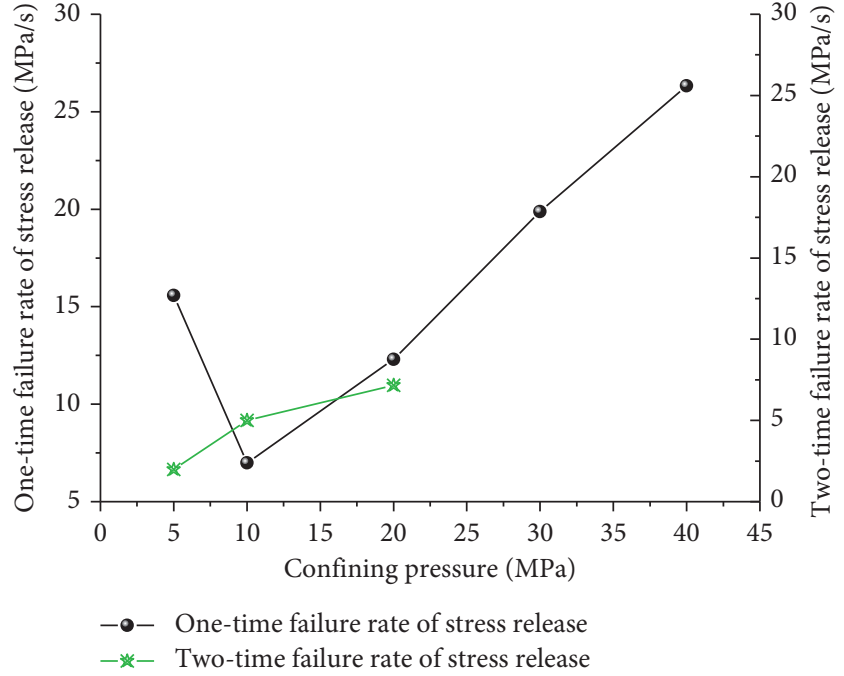

FIgURE 7: Relation between stress release rate and confining pressure of rock fracture.

to expand, and the body strain continued to decrease, indicating that the circumferential change rate was less than the axial change rate. When the body strain stayed the same (1987 s), it indicates that the rate of axial change was consistent with the rate of change of the circumferential direction. Meanwhile, it was considered as a time of early warning of damage. Then, the expansion of the rock sample occurred, followed by destruction, and the body strain was greater than the initial value. After the occurring of a failure, it was found that the stress was stable and the strain changed. When it entered into the phase of simultaneous unloading of axial pressure and confining pressure, due to the difference of initial unloading stress, the overall axial loading and confining pressure unloading would occur, which was also the essential reason for secondary damage. The axial strain increases and the circumferential deformation continuously expanded. It can be seen from the body strain at this time that the circumferential speed of change was greater than that of the axial direction. The circumferential deformation reached the monitoring limit at specific moment. At this time, the instability information could not be judged by the circumferential change. Because there was a hoop strain in the body strain, only the axial strain could be used to evaluate the process information of the rock sample. There was a change of the slope of the axial strain at $2759 \mathrm{~s}$, indicating that the rock specimen was about to undergo secondary damage and secondary damage occurred in $2827 \mathrm{~s}$. Confining pressure is unloaded to zero. The axial strain limit was 2.92. The results of the initial stage of the initial loading of the $10 \mathrm{MPa}$ hydrostatic pressure rock sample and the $5 \mathrm{MPa}$ rock sample peak were similar. However, there was no significant change occurring in the axial deformation and the circumferential deformation during the initial stage of axial unloading after the peak. This shows that the axial stress unloading speed and the hoop stress unloading speed were exactly the same. Meanwhile, it can be found that the state of stress was always in a stable state. After the unloading, the axial deformation decreased and then 


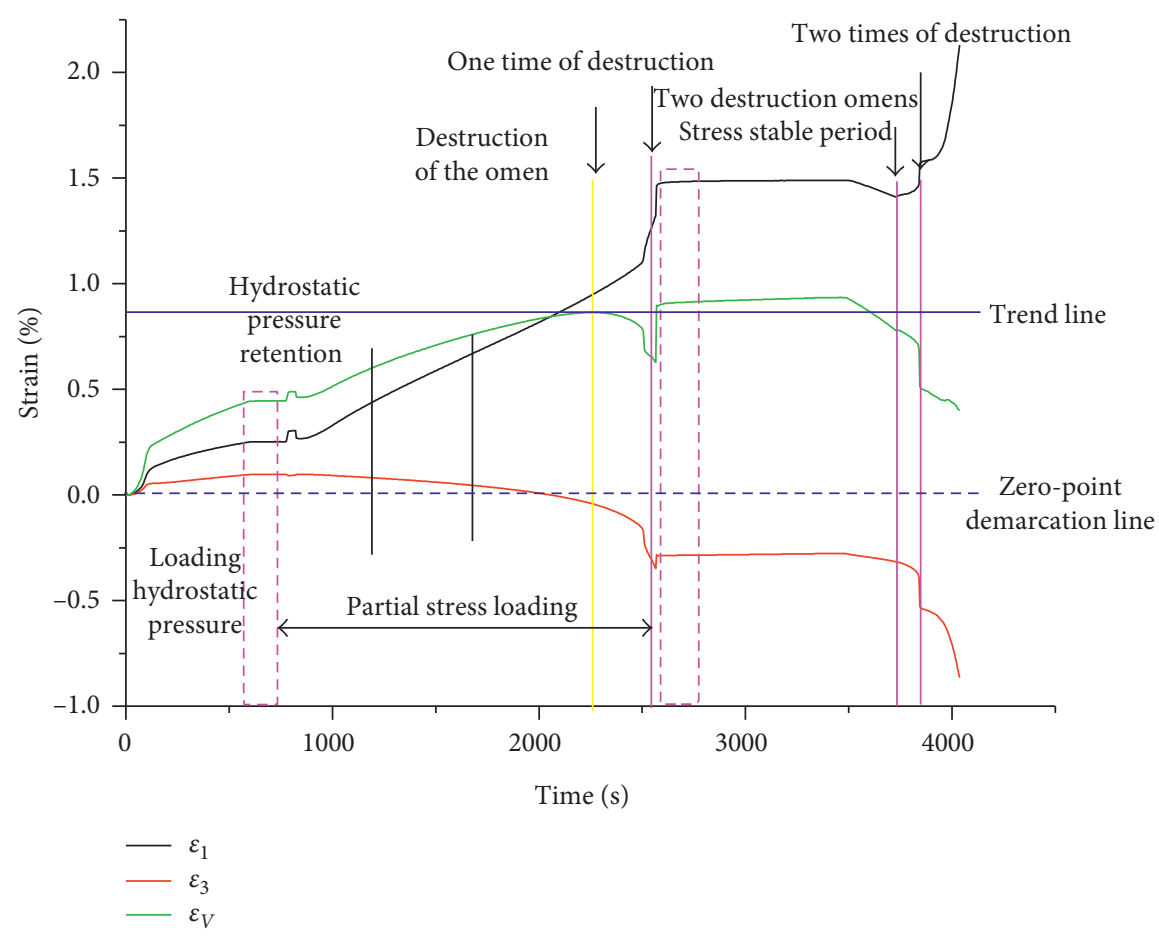

(a)

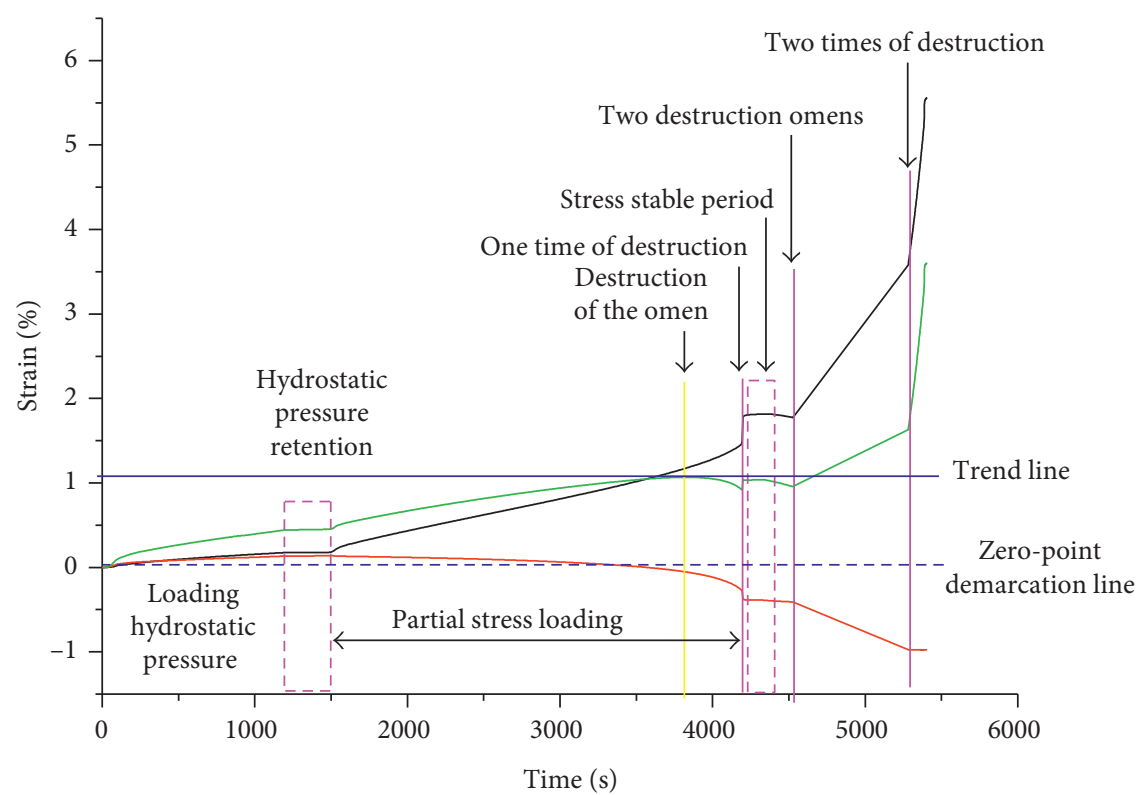

(b)

FIgUre 8: Continued. 


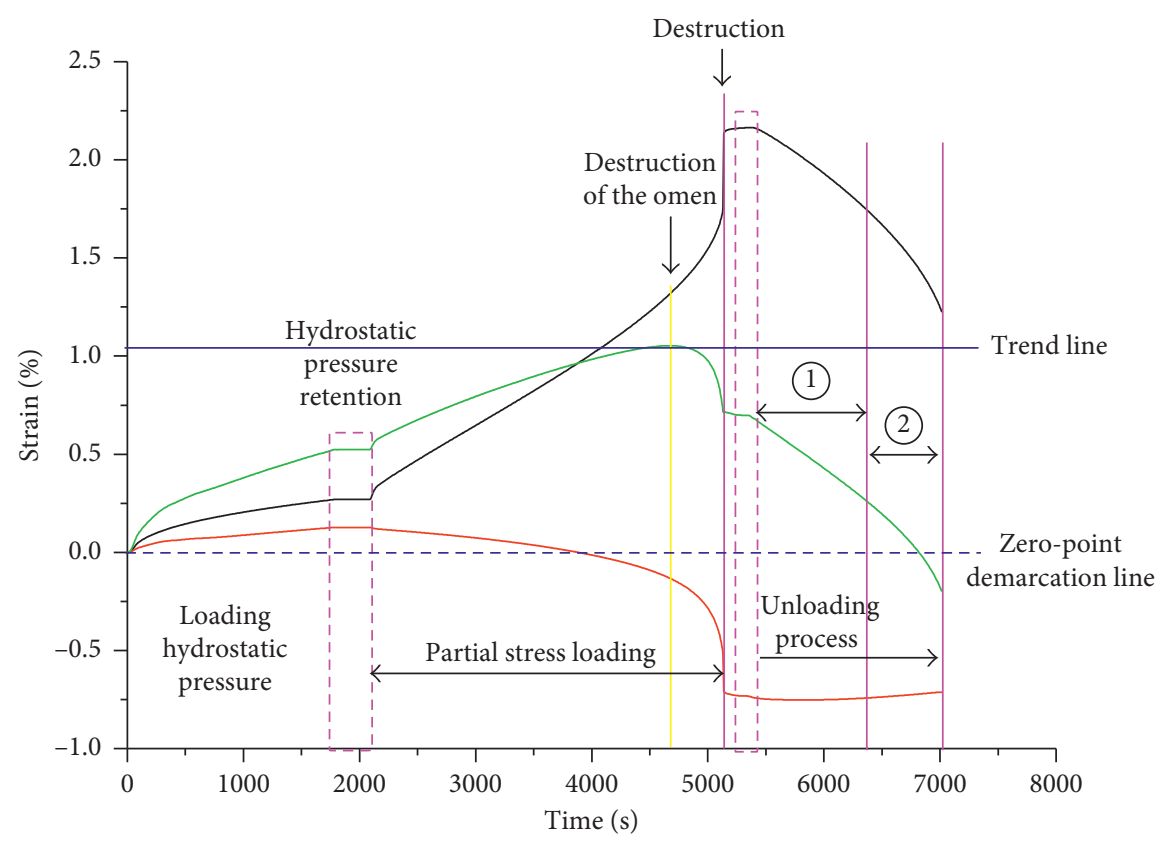

$$
\begin{array}{r}
-\varepsilon_{1} \\
-\varepsilon_{3} \\
-\varepsilon_{V}
\end{array}
$$

(c)

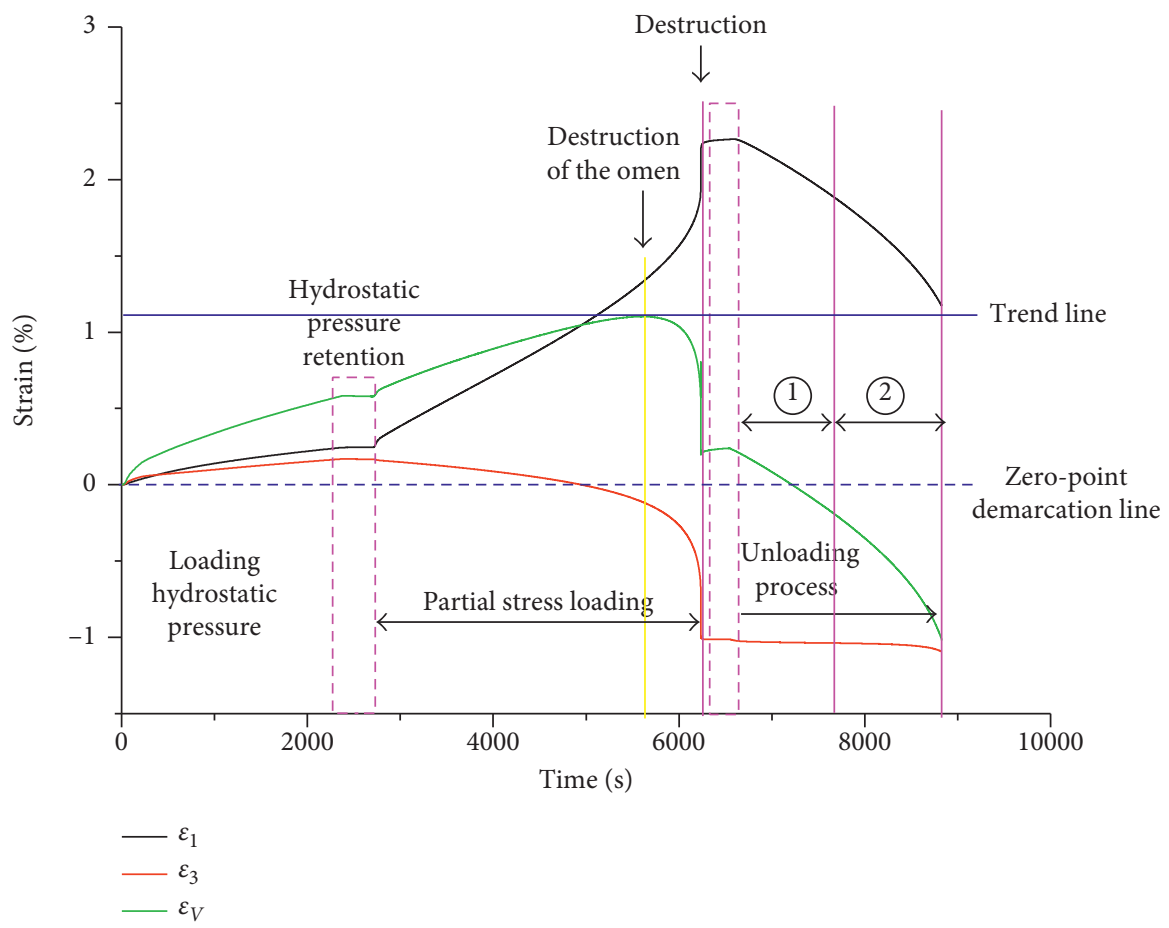

(d)

FIgUre 8: Continued. 


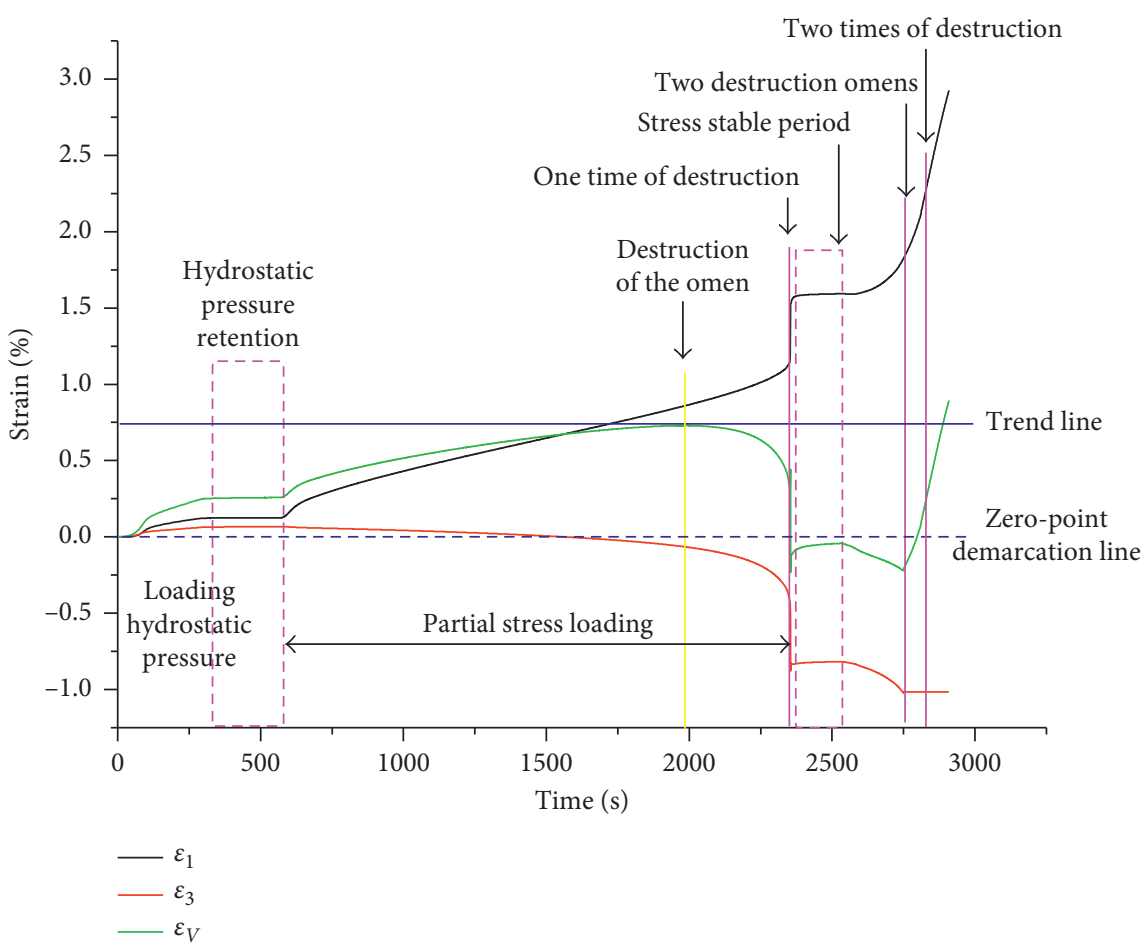

(e)

FIGURE 8: Curves of strain versus time under different confining pressures. (a) Change law of strain-time curve of surrounding rock at $5 \mathrm{MPa}$. (b) Strain-time curve of surrounding rock at $10 \mathrm{MPa}$. (c) Change law of strain-time curve of surrounding rock at $20 \mathrm{MPa}$. (d) Variation rule of strain-time curve for wall rocks at $30 \mathrm{MPa}$. (e) Variation rule of strain-time curve for surrounding rocks at $40 \mathrm{MPa}$.

increased. The circumferential deformation increased. Afterward, secondary damage occurred. This time, the demarcation points of the decrease and increase of the axial strain were defined as the premonitory moment of the secondary failure. The results of the rock samples loaded to $20 \mathrm{MPa}$ hydrostatic pressure were similar to those of the $5 \mathrm{MPa}$ rock samples, which are not analyzed here. The peak of the rock sample before the occurrence of secondary failure was consistent with that of other rock samples. The unloading process of the rock sample with initial hydrostatic pressure of $30 \mathrm{MPa}$ exhibited two-stage characteristics. The ring strain of process 1 remained basically unchanged, while there was a continuous decrease of the axial strain. Expansion shows that the axial unloading speed was faster, and axial and circumferential unloading had less effect on the steady state of the ring. In process 2 , the circumferential strain gradually decreased. Besides, the axial strain still decreased. The volume expansion rate slowed down. This indicated that both the axial direction and the circumferential direction were unloaded, and the axial direction still played a leading role. The rock sample with the initial hydrostatic pressure of $40 \mathrm{MPa}$ was consistent with the process 1 of the rock sample with initial hydrostatic pressure of $30 \mathrm{MPa}$. Meanwhile, process 2 showed a tendency of gradual increase in hoop strain. This shows that the rock sample as a whole showed an axially unloaded and circumferentially loaded state. With the increase of hydrostatic pressure, the body strain of the rock sample was also increasing. When the pressure was lower, the increase was faster, and when the pressure was higher, the increase was more stable.

\subsection{Synchronization Unloading Energy Change Characteris-} tics Analysis. According to the energy calculation method in the theoretical basis of Section 2.4, the elastic energy accumulated before the peak. Afterward, it was released after the peak. An analysis about the elastic energy released by the first failure and secondary damage, the energy release rate, the remaining energy, and the plastic coefficient is shown in Table 2. For a clear analysis of the problem, Figure 9 displays the stress-strain-time diagram of confining pressure $10 \mathrm{MPa}$ rock samples, and Figure 10 gives the stress-strain-time diagram of confining pressure $40 \mathrm{MPa}$ rock samples. The calculation methods and ideas under other confining pressures are the same and are not repeated.

By analyzing the characteristics of energy conversion under low confining pressure and energy conversion characteristics under high confining pressure, it can be found that there is similarity before peak. The initial strain existed under the influence of hydrostatic pressure, and the elastoplastic section was obvious, during the process of which the rock sample was continuously storing the strain energy. Afterward, the fracture occurred and the energy was released instantaneously. High confining pressure rocks released more energy compared the total amount of energy generated under low confining pressure. In the initial phase of simultaneous unloading, convex curves appeared. High confining pressure 


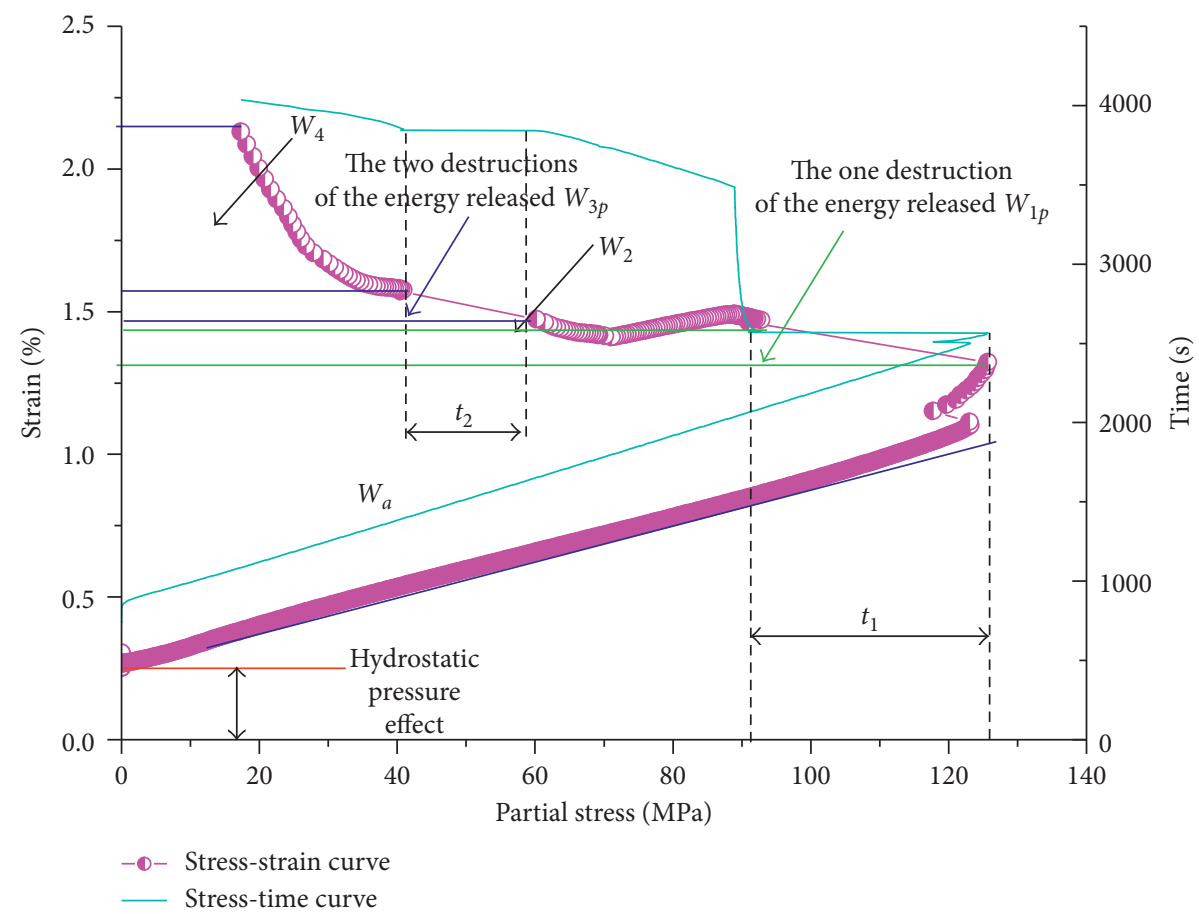

FiguRE 9: Energy conversion curve of rock sample under confining pressure of $10 \mathrm{MPa}$.

and low confining pressure have demonstrated obvious differences in the later period. The deformation of the low confining pressure curve increased, and the strain energy is continuously released. In the event of a second rupture, less energy was instantaneously released and then the energy continued to release until the confining pressure reached zero. There was a certain amount of residual stress while the energy release reached the end point. The deformation of the high confining pressure curve was continuously decreasing. Meanwhile, the rock sample was continuously absorbing energy until it reached the confining pressure zero point and the energy absorption was completed.

Based on the analysis of the strain energy stored before the peak under different confining pressures, it can be seen that with the increase of confining pressure, the energy stored before the peak is increasing. The conclusion is consistent with objective reality. The greater the constraints on rock samples are, the more energy they can store. The strain energy released after the peak does not have regularity. When the confining pressure was $5 \mathrm{MPa}$, the released energy was greater than the absorbed energy. Due to the large fragmentation of the block, the external input energy leads to the release of self-energy. The energy released after the peak of the secondary fractured rock sample decreases and then increases corresponding with the increase of the confining pressure. The energy released by the first destruction and the energy released by $W_{2}$ also satisfied the above rules. The law of the energy released by the secondary destruction and the energy released by $W_{4}$ was exactly the opposite, showing a trend of increase and decrease afterward. The energy that was released after the peak of the rock sample without secondary damage was decreasing along with the increase of confining pressure. The energy released after the destruction also satisfied the above rules. The law of change of $W_{2}$ was contrary to it, presenting an increasing trend. The strain energy absorbed by $W_{4}$ increased continuously. The release velocity of the first destructive energy tended to decrease first and then increased with confining pressure. The rate of release of secondary destructive energy continued to increase. As the confining pressure increases, the remaining energy appeared to increase first, then decrease and finally increase. The result is the reason why disasters under high stress in deep mining are highlighted. The plasticity coefficient showed a trend of increase first and then decrease. When the confining pressure was $20 \mathrm{MPa}$, the plasticity coefficient of yellow sandstone was equal to 1 .

\subsection{Simultaneous Unloading Damage Change Characteristics} Analysis. According to formula (11), the damage variable is normalized while the damage variable $D$ based on the cumulative energy of acoustic emission is obtained. The curve of the deviatoric stress and damage variable over time in the process of synchronous unloading under triaxial conditions is given. Because of the similarity between the high confining pressure and the low confining pressure results, the curves corresponding to confining pressures of $10 \mathrm{MPa}$ and $40 \mathrm{MPa}$ were selected for analysis.

As can be seen from Figure 11, the curve can be divided into eight phases. In the first stage, the hydrostatic pressure made the original pores and microfissures of the rock sample closed. At this point, the acoustic emission signal was less and the energy was smaller. The damage variable had a small increase. In the second stage, deviatoric stress loading caused the original cracks to continuously expand. At the same time, new cracks are generated. At this point, a certain 


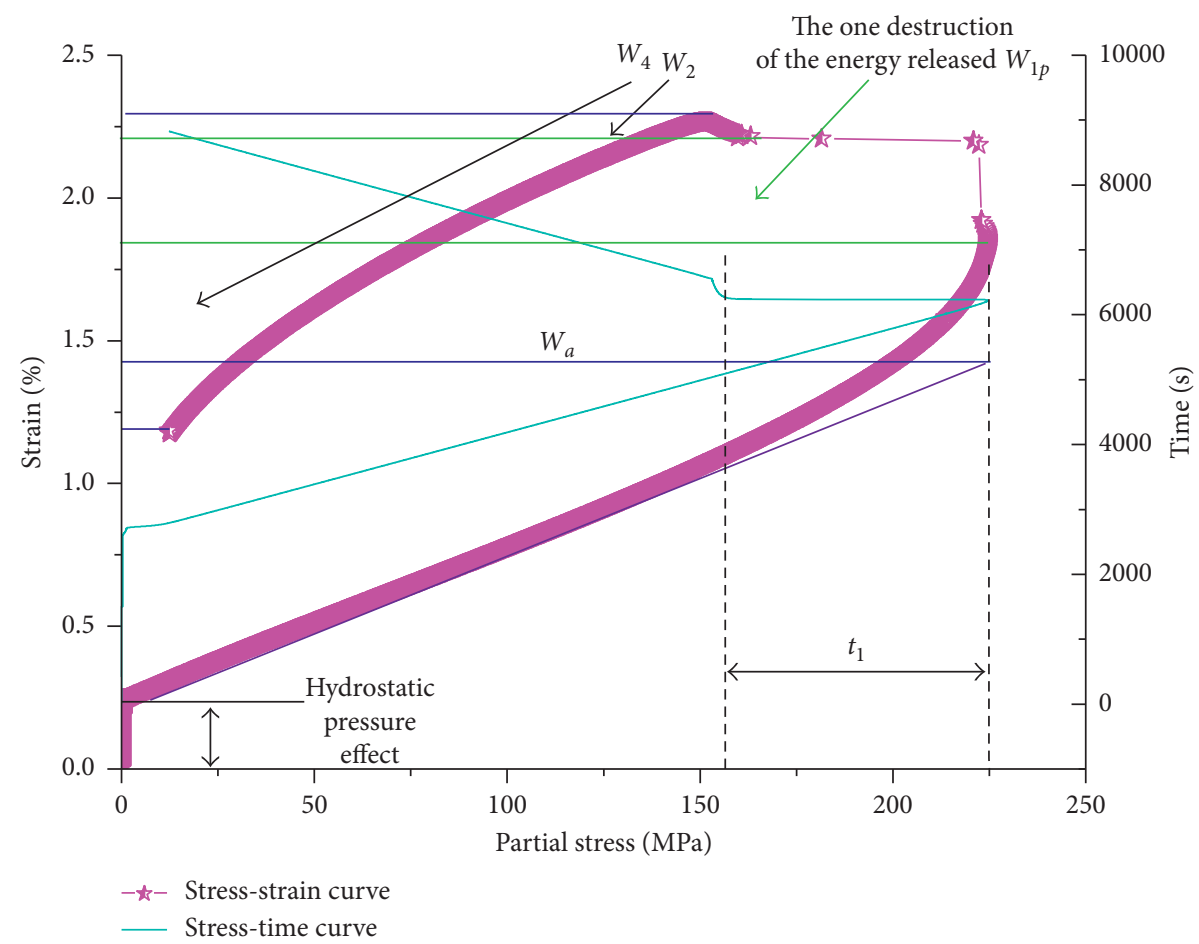

Figure 10: Energy conversion curve of rock sample under confining pressure of $40 \mathrm{MPa}$.

amount of acoustic emission signals was received while the energy was increased. Additionally, the damage variable was in a slow growth stage. In the third stage, the microcracks caused by the first destruction continuously penetrated into the main control cracks. At this time, the acoustic emission activity was intense and the energy was extremely high. The damage variable was in a rapid growth stage. $72.91 \%$ of the damage was caused by the initial destruction. In the fourth stage, simultaneous unloading resulted in a more stable resultant force and no new cracks appeared or expanded. At this point, the acoustic emission signal was minimal and the energy was minimal. The damage variable was in a stable phase. In the fifth stage, the stress difference caused by simultaneous unloading made the rock sample unstable, and microcracks initiated and expanded. Both the acoustic emission signal and energy demonstrate the increasing trend at this time. Meanwhile, the damage variable was in a rapid growth phase. At this point, it could be predicted that the rock sample would undergo secondary damage. In the sixth stage, the microcrack expansion caused by the secondary damage was lost to the bearing capacity. At this time, the acoustic emission activity was intense and the energy was very large, and the damage variable was in a rapid growth phase. About $10 \%$ of damage was caused by secondary damage. In the seventh and eighth stages, the axial pressure was greater than the confining pressure and the fracture was further aggravated. At this time point, the acoustic emission activity was more intense and the energy was larger, and the damage variable was in a stage of slow growth and rapid growth.

As can be seen from Figure 12, the curve can be divided into five stages. The first, second, and third stages were similar to the low confining pressure rock samples, but the growth rate of the damage variable was greater than that of the low confining pressure. The results were in line with the actual situation. The rock fracture could be predicted by the rapid growth of the second-stage damage variable. About $88 \%$ of damage was caused by destruction. The fourth phase was the stable period before synchronous unloading. No new cracks appeared and spread. At this point, the acoustic emission signal was minimal and the energy was minimal, and the damage variable was in a stable phase. In the fifth stage, the axial unloading caused by the simultaneous unloading was greater than the confining pressure and the fracture was further aggravated, making the rock sample unstable. At this time, the acoustic emission activity was more intense and the energy was larger, and the damage variable was in a slow growth stage.

\subsection{Analysis of Unloading Damage Precursor Information} Based on Rock Mechanics Characteristics, Energy Conversion Characteristics, and Damage Evolution Law. The precursory information of the primary damage is consistent with other research results and will not be discussed here. The secondary damage precursor information caused by excavation unloading is of great significance to the safety and stability control of the project. There is an abnormal stage in the early stage of rock failure. The deformation anomaly, energy anomaly, and damage anomaly are analyzed to comprehensively evaluate the precursor characteristics of the secondary failure of rock mass.

It is obtained in the analysis in Section 3.2 that primary failure causes large radial deformation, which causes the 


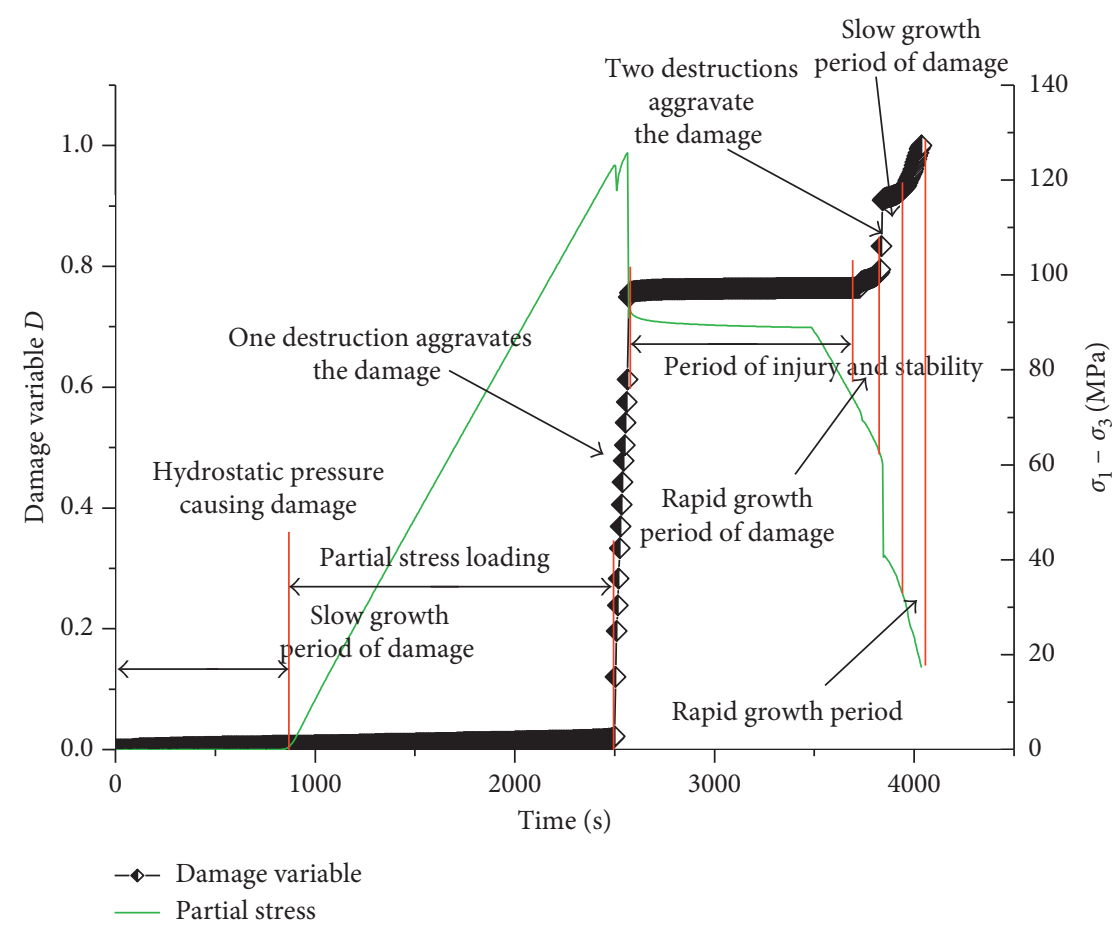

Figure 11: Damage evolution curve of rock sample under confining pressure of $10 \mathrm{MPa}$.

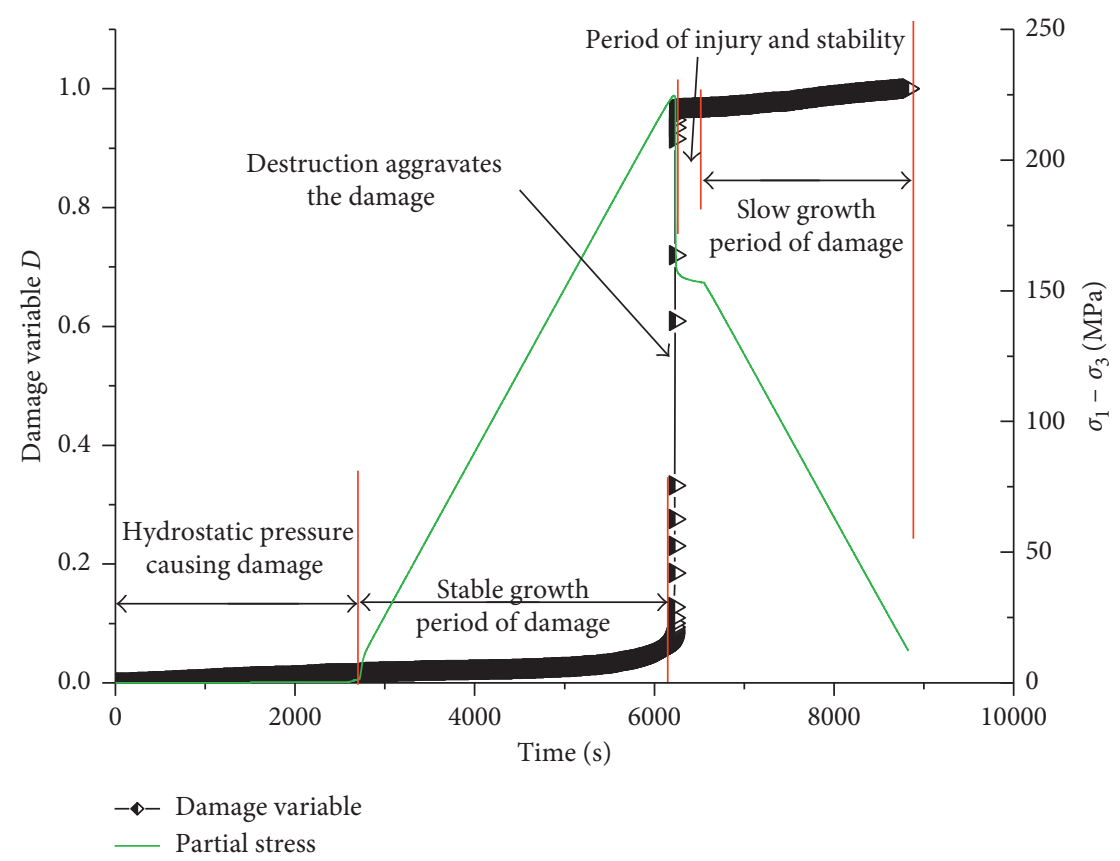

Figure 12: Damage evolution curve of rock sample under confining pressure of $40 \mathrm{MPa}$.

toroidal sensor to reach or exceed the limit. There is a certain deviation in the radial deformation or the physical strain evaluation. The axial strain is used to analyze the secondary damage precursor of the rock. By analyzing the samples of the confining pressures of $5 \mathrm{MPa}, 10 \mathrm{MPa}$, and $20 \mathrm{MPa}$, it can be inferred that the secondary damage will occur when the axial strain slope changes. The axial strain slope of the $5 \mathrm{MPa}$ sample at 2759 s was changed, and the secondary damage occurred at $2827 \mathrm{~s}$. The energy release process during the peak unloading process of the $5 \mathrm{MPa}$ sample was analyzed. The energy release process approximated the S-shaped curve. The energy release jump point appeared in the second stage of the secondary failure. The moment occurred at $2812 \mathrm{~s}$, which indicates that energy release predicts the precursory characteristics of the damage. Before the secondary failure of the rock sample, there is a rapid growth period of damage 
evolution. The damage evolution increase time is $2691 \mathrm{~s}$, and the second damage occurs after $136 \mathrm{~s}$, indicating that the damage can be predicted by accelerating growth of damage evolution. From the perspective of deformation, energy, and damage, it is found that the first feedback in the secondary rupture of the rock sample is the acceleration of the damage parameter, and then, the feedback is the inflection point of the axial strain slope. Finally, the feedback is the energy release jumping. The above parameters all made abnormal feedback before the second rupture, which can comprehensively judge the arrival of instability, and it has certain guiding significance for the scene.

\section{Conclusion}

In this paper, the triaxial tester and acoustic emission system of France were used to perform the postpeak simultaneous unloading of the peak pressure and confining pressure in the yellow sandstone. The mechanical characteristics, energy conversion characteristics, and damage evolution of yellow sandstone in a primary and secondary destruction process are obtained. Meanwhile, the following rules are generated:

(1) When the confining pressure was $5 \mathrm{MPa}, 10 \mathrm{MPa}$, and $20 \mathrm{MPa}$, secondary failure occurred. However, no secondary failure occurred when the confining pressure was $30 \mathrm{MPa}$ and $40 \mathrm{MPa}$. After the destruction of the rock, it requires specific adjustment and a certain pressure drop occurs. The degree of secondary rupture and the number of cracks are larger than those without secondary damage. When the secondary unloading is induced by synchronous unloading, the corresponding confining pressure value, the pressure difference during secondary damage, the time of secondary failure, and the stress reduction value during failure are all different. The problem of secondary damage in engineering should be handled with care.

(2) The stress release rate of the initial failure is obvious, showing the trend of " $\sqrt{ }$." With the increase of confining pressure, the stress release rate of secondary failure rock samples increases correspondingly.

(3) The law of strain change of the secondary failure occurs as follows: Through the body strain remains unchanged, it is determined as a breakage warning time. Due to the difference in initial unloading stress, the overall axial loading and confining pressure unloading occur. This serves as the essential reason for secondary damage. Through the inflection point of the axial strain slope, the secondary failure of the rock is predicted. The two-stage characteristics of rock sample strain unloading without secondary failure occur. As the hydrostatic pressure increases, the body strain increases correspondingly. When the pressure is lower, the increase is faster, and when the pressure is higher, the increase is steady.

(4) As the confining pressure increases, the energy stored before the peak increases continuously. For the rock samples with secondary failure, the energy released after the peak increases with the confining pressure first decreasing and then increasing. The law of releasing energy at the initial destruction is the opposite of the law of secondary destruction of energy. With the increase of confining pressure, the energy released after the peak of the rock that has not undergone the secondary destruction is continuously decreasing. The release velocity of the first destructive energy tends to decrease first and then increase with the increase of the confining pressure. The rate of release of secondary destructive energy continues to increase. As the confining pressure increases, the remaining energy shows a tendency of fluctuating growth. The coefficient of plasticity shows a trend of increasing first and then decreasing.

(5) The damage evolution law of rock samples with secondary damage is divided into eight stages: the stage of small increase of damage variable, slow growth of damage variable, rapid increase of damage variable, stability of damage variable, rapid increase of damage variable, rapid growth of damage variable, slow growth of damage variable, and rapid growth. The damage evolution of rock specimens without secondary damage is divided into five stages: smallscale increase of damage variable, slow increase of damage variable, rapid growth of damage variable, steady state of damage variable, and slow growth of damage variable. The secondary damage of the rock sample with secondary failure is superposed less than the damage degree of the rock sample with one failure.

\section{Data Availability}

The data used to support the findings of this study are available from the corresponding author upon request.

\section{Conflicts of Interest}

The authors declare that they have no conflicts of interest.

\section{Acknowledgments}

This research was supported by the National Natural Science Foundation of China (51574115, 51674107, 51774121, 51604100, and 51674109). The authors would like to thank all members for their help with the fieldwork in Heilongjiang Ground Pressure \& Gas Control in Deep Mining Key Lab (GPGC).

\section{References}

[1] M.-C. He, F. Zhao, S. Du et al., "Rockburst characteristics based on experimental tests under different unloading rates," Rock and Soil Mechanics, vol. 35, no. 10, pp. 2737-2747, 2014, in Chinese.

[2] M.-C. He, X.-N. Jia, M. Coli et al., "Experimental study of rockbursts in underground quarrying of Carrara marble," International Journal of Rock Mechanics and Mining Sciences, vol. 52, pp. 1-8, 2012. 
[3] M.-C. He, J.-L. Miao, D.-J. Li et al., "Experimental study on rockburst processes of granite specimen at great depth," Chinese Journal of Rock Mechanics and Engineering, vol. 26, no. 5, pp. 865-876, 2007, in Chinese.

[4] M.-C. He, J.-L. Miao, and J. L. Feng, "Rock burst process of limestone and its acoustic emission characteristics under true-triaxial unloading conditions," International Journal of Rock Mechanics and Mining Sciences, vol. 47, no. 2, pp. 286-298, 2010.

[5] S.-C. Xu, X.-T. Feng, and B.-R. Chen, "Experimental study of skarn under uniaxial cyclic loading and unloading test and acoustic emission characteristics," Rock and Soil Mechanics, vol. 30, no. 10, pp. 2929-2934, 2009, in Chinese.

[6] J. Zhou, X. Yang, W. Fu et al., "Experimental test and fracture damage mechanical characteristics of brittle rock under uniaxial cyclic loading and unloading conditions," Chinese Journal of Rock Mechanics and Engineering, vol. 29, no. 6, pp. 1172-1183, 2010, in Chinese.

[7] H. Deng, Y. Hu, J. Li et al., "The evolution of sandstone energy dissipation under cyclic loading and unloading," Chinese Journal of Rock Mechanics and Engineering, vol. 35, no. S1, pp. 2869-2875, 2016, in Chinese.

[8] H. Deng, Y. Hu, J. Li et al., "Experimental research on the load/unload response ratio considering the hysteresis effect of rock," Chinese Journal of Rock Mechanics and Engineering, vol. 34, no. S1, pp. 2915-2921, 2015, in Chinese.

[9] D. Z. Song, E. Y. Wang, and J. Liu, "Relationship between EMR and dissipated energy of coal rock mass during cyclic loading process," Safety Science, vol. 50, no. 4, pp. 751-760, 2012.

[10] G. Yin, W. Li, M. Li et al., "Experimental study of mechanical properties of coal containing methane under different loading-unloading conditions," Chinese Journal of Rock Mechanics and Engineering, vol. 32, no. 5, pp. 891-901, 2013, in Chinese.

[11] S. K. Ray, M. Sarkar, and T. N. Singh, "Effect of cyclic loading and strain rate on the mechanical behavior of sandstone," International Journal of Rock Mechanics and Mining Sciences, vol. 36, no. 4, pp. 543-549, 1999.

[12] M. N. Bagde and V. Petros, "Fatigue and dynamic energy behaviour of rock subjected to cyclical loading," International Journal of Rock Mechanics and Mining Sciences, vol. 46, no. 1, pp. 200-209, 2009.

[13] X. Zhao, P. Li, L. Ma et al., "Damage and dilation characteristics of deep granite at beishan under cyclic loading-unloading conditions," Chinese Journal of Rock Mechanics and Engineering, vol. 33, no. 9, pp. 1740-1748, 2014, in Chinese.

[14] L.-P. Liu, X.-G. Wang, Z.-X. Jia et al., "Experiment study of marble mechanical properties of Jinping II hydropower station under complex loading and unloading conditions," Rock and Soil Mechanics, vol. 34, no. 8, pp. 2287-2294, 2013, in Chinese.

[15] H. Zhou, Z. Shan, W. Li et al., "Study of true triaxial strength parameters in unloading path of marbles in deep tunnel," Chinese Journal of Rock Mechanics and Engineering, vol. 31, no. 8, pp. 1524-1529, 2012, in Chinese.

[16] H.-P. Wang, J.-H. Xue, J.-M. Li et al., "Simulation of dynamic response of surrounding rock under the tunneling-induced unloading," Rock and Soil Mechanics, vol. 36, no. 5, pp. 1481-1487, 2015, in Chinese.

[17] S. Wu, Y. Zhou, B. Gao et al., "Study of unloading tests of rock burst and pfc3d numerical simulation," Chinese Journal of Rock Mechanics and Engineering, vol. 29, no. S2, pp. 40824088, 2010, in Chinese.
[18] J. Xu, H. Yang, S. Li et al., "Experimental study of effects of cyclic loading and unloading pore water pressures on deformation characteristic of sandstone," Chinese Journal of Rock Mechanics and Engineering, vol. 28, no. 5, pp. 892-899, 2009, in Chinese.

[19] M. Wang, P. Fan, W. Li et al., "Mechanism of splitting and unloading failure of rock," Chinese Journal of Rock Mechanics and Engineering, vol. 29, no. 2, pp. 234-241, 2010, in Chinese.

[20] C.-H. Yang, H.-L. Ma, J.-F. Liu et al., "Study of deformation of rock salt under cycling loading and unloading," Rock and Soil Mechanics, vol. 30, no. 12, pp. 3562-3568, 2009, in Chinese.

[21] F. Xiao, Z. Shen, G. Liu et al., "Relationship between hysteresis loop and elastoplastic strain energy during cyclic loading and unloading," Chinese Journal of Rock Mechanics and Engineering, vol. 33, no. 9, pp. 1791-1797, 2014, in Chinese.

[22] F. Xiao, G. Liu, Z. Shen et al., "Research on effective elastic energy release rate of Taoshan \#90 coal seam," Chinese Journal of Rock Mechanics and Engineering, vol. 34, no. S2, pp. 4216-4225, 2015, in Chinese.

[23] F. Xiao, L. Gang, Z. Sehn et al., "Energy conversion and acoustic emission (AE) characteristics of coal samples under cyclic loading," Chinese Journal of Rock Mechanics and Engineering, vol. 35, no. 10, pp. 1954-1964, 2016, in Chinese.

[24] G. Liu, L. Li, F. Xiao et al., "Numerical analysis of rock burst tendency for "three hard" coal and rock combination," Safety in Coal Mines, vol. 47, no. 8, pp. 198-200, 2016, in Chinese.

[25] G. Liu, Y. Zhang, Z. Shen et al., "Granite damage acoustic emission evaluation," Journal of Heilongjiang University of Science \& Technology, vol. 25, no. 6, pp. 615-620, 2015, in Chinese.

[26] Y. Yang, D. Wang, G. Mingfu et al., "Study of rock damage characteristics based on acoustic emission tests under triaxial compression," Journal of Heilongjiang University of Science \& Technology, vol. 33, no. 1, pp. 98-104, 2014, in Chinese.

[27] H. L. Liu, L. C. Li, Z. C. Li, and G. Yu, "Numerical modelling of mining-induced inrushes from subjacent water conducting karst collapse columns in northern China," Mine Water and the Environment, vol. 36, pp. 1-11, 2017.

[28] Z. C. Li, L. C. Li, M. Li et al., "A numerical investigation on the effects of rock brittleness on the hydraulic fractures in the shale reservoir," Journal of Natural Gas Science and Engineering, vol. 50, pp. 22-32, 2018. 


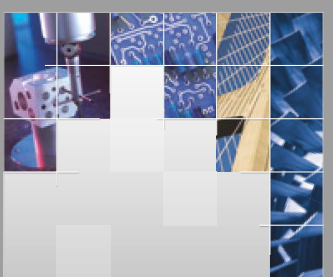

\section{Enfincering}
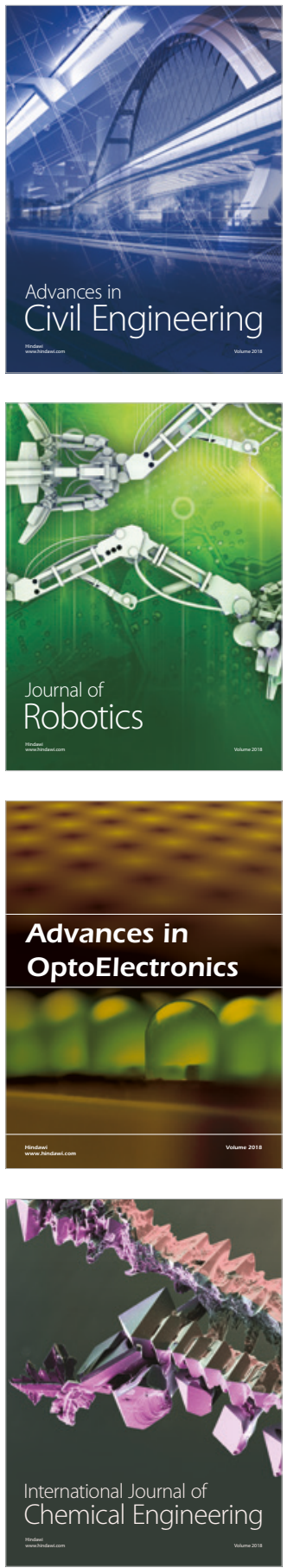

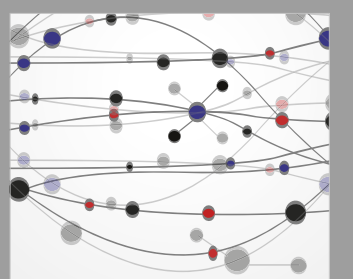

\section{Rotating \\ Machinery}

The Scientific World Journal

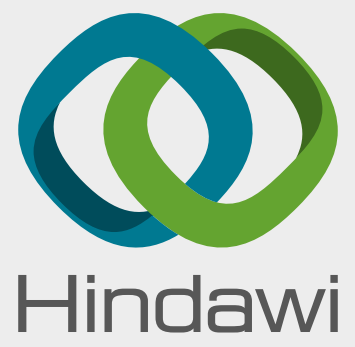

Submit your manuscripts at

www.hindawi.com
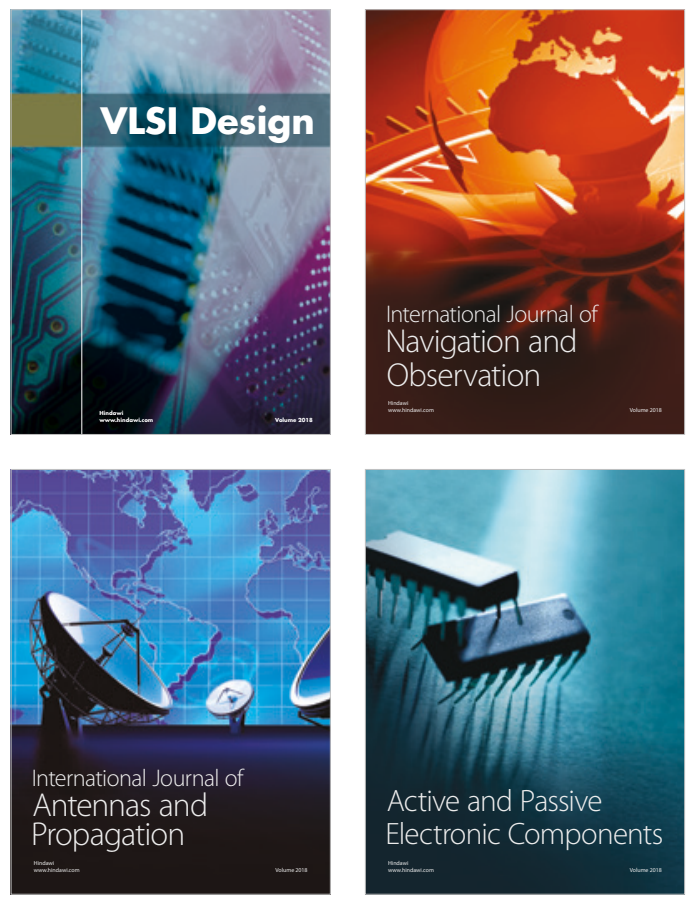
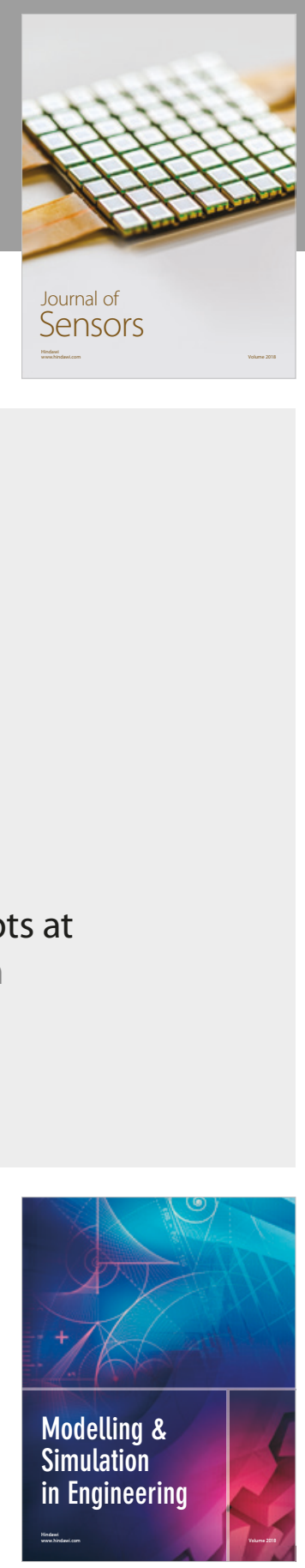

\section{Advances \\ Multimedia}
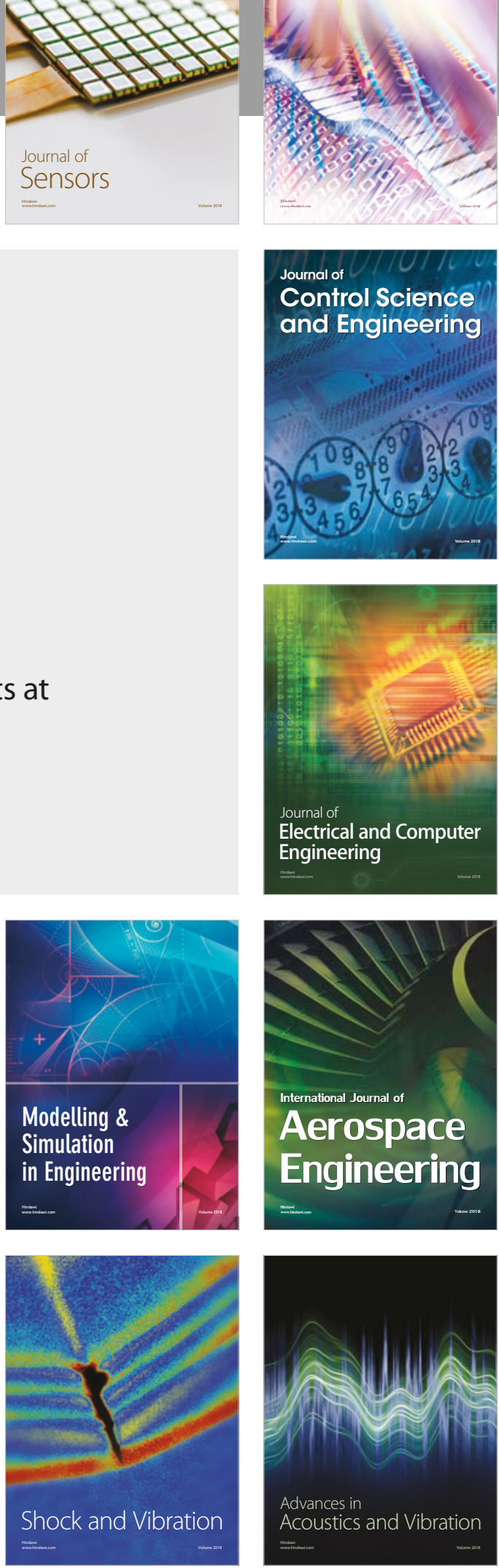